OPEN ACCESS

Edited by:

Kevin G. Bath,

Brown University, United States

Reviewed by:

Samantha L. Baglot,

University of Calgary, Canada

Russell D. Romeo,

Columbia University, United States

*Correspondence:

Ratna Angela Sarabdjitsingh r.a.sarabdjitsingh@umcutrecht.nl

Received: 19 April 2019

Accepted: 19 July 2019

Published: 07 August 2019

Citation:

Bonapersona $V$, Damsteegt $R$, Adams ML, van Weert LTCM, Meijer OC, Joëls M and Sarabdjitsingh RA

(2019) Sex-Dependent Modulation of Acute Stress Reactivity After Early Life Stress in Mice: Relevance of Mineralocorticoid

Receptor Expression. Front. Behav. Neurosci. 13:181. doi: 10.3389/fnbeh.2019.00181

\section{Sex-Dependent Modulation of Acute Stress Reactivity After Early Life Stress in Mice: Relevance of Mineralocorticoid Receptor Expression}

\author{
Valeria Bonapersona ${ }^{1}$, Ruth Damsteegt ${ }^{1}$, Mirjam L. Adams ${ }^{1}$, Lisa T. C. M. van Weert ${ }^{2}$, \\ Onno C. Meijer ${ }^{2}$, Marian Joëls ${ }^{1,3}$ and Ratna Angela Sarabdjitsingh ${ }^{1 *}$ \\ ${ }^{1}$ Department of Translational Neuroscience, UMC Utrecht Brain Center, Utrecht University, Utrecht, Netherlands, \\ ${ }^{2}$ Department of Internal Medicine, Leiden University Medical Center, Division of Endocrinology, Leiden, Netherlands, \\ ${ }^{3}$ University Medical Center Groningen, University of Groningen, Groningen, Netherlands
}

Early life stress (ELS) is considered a major risk factor for developing psychopathology. Increasing evidence points towards sex-dependent dysregulation of the hypothalamicpituitary-adrenal (HPA) axis as a contributing mechanism. Additionally, clinical studies suggest that the mineralocorticoid receptor (MR) may further confer genetic vulnerability/resilience on a background of ELS. The link between ELS, sex and the HPA axis and how this interacts with MR genotype is understudied, yet important to understand vulnerability/resilience to stress. We used the early life-limited nesting and bedding model to test the effect of ELS on HPA properties in adult female and male mice carrying a forebrain-specific heterozygous knockout for MR. Basal HPA axis activity was measured by circadian peak and nadir corticosterone levels, in addition to body weight and weight of stress-sensitive tissues. HPA axis reactivity was assessed by mapping corticosterone levels after $10 \mathrm{~min}$ immobilization. Additionally, we measured the effects of ELS on steroid receptor [MR and glucocorticoid receptor (GR)] levels in the dorsal hippocampus and medial prefrontal cortex (mPFC) with western blot. Finally, behavioral reactivity towards a novel environment was measured as a proxy for anxiety-like behavior. Results show that HPA axis activity under rest conditions was not affected by ELS. HPA axis reactivity after immobilization was decreased by ELS in females and increased, at trend-level in males. This effect in females was further exacerbated by low expression of the MR. We also observed a sex*ELS interaction regarding MR and GR expression in the dorsal hippocampus, with a significant upregulation of MR in males only. The sex-dependent interaction with ELS was not reflected in the behavioral response to novel environment and time spent in a sheltered compartment. We did find increased locomotor activity in all groups after a history of ELS, which attenuated after $4 \mathrm{~h}$ in males but not females regardless of condition. Our findings support that ELS alters HPA axis functioning sex-dependently. 
Genetic predisposition to low MR function may render females more susceptible to the harmful effect of ELS whereas in males low MR function promotes resilience. We propose that this model may be a useful tool to investigate the underlying mechanisms of sex-dependent and genetic vulnerability/resilience to stress-related psychopathology.

Keywords: mineralocorticoid receptor, early life stress (ELS), HPA axis, neuroendocrine, behavior, corticosterone, sex, nuclear receptors

\section{INTRODUCTION}

Early life is a sensitive developmental period, during which stress experienced early in life (early life stress, ELS), may induce long-lasting consequences for the ability to deal with challenging situations later in life (Heim et al., 2008; Strüber et al., 2014). ELS is known to affect both basal and stress-induced hypothalamuspituitary-adrenal (HPA) axis activity (van Bodegom et al., 2017). This most likely occurs through gradual but persistent changes in HPA axis circuitry and the wiring of other neural networks involved in cognitive and emotional functioning (Andersen, 2003; Lupien et al., 2009).

Dysregulation of the HPA axis is considered to be an important risk factor for mental illnesses such as major depression and anxiety disorders (de Kloet et al., 1998; Varghese and Brown, 2001; Young et al., 2004; Pariante and Lightman, 2008; Moreno-Peral et al., 2014). Ample evidence associates changes in HPA axis function with depression or anxiety disorders, both with respect to circadian rhythmicity, response to the dexamethasone-CRH test or cortisol responses evoked by psychosocial stress (Künzel et al., 2003; Pariante and Lightman, 2008; Keller et al., 2017; Zorn et al., 2017). This body of literature includes observations in high-risk proband of women with depression, who do not (yet) show any symptoms of depression themselves (Modell et al., 2005), suggesting a causative role of HPA axis disturbances in the precipitation of depressive symptoms. Interestingly, a recent meta-analysis revealed that the association between stress-induced cortisol responses and stress-related psychopathology is sex-dependent: women with depression or anxiety disorders overall showed a blunted response to psychosocial stress (i.e., the Trier social stress test, TSST), whereas men showed the opposite (Zorn et al., 2017). Of note, women exposed to ELS also showed a blunted response to the TSST (Carpenter et al., 2011), while DeSantis et al. (2011) demonstrated a sex-dependent interaction between ELS and the response to $\mathrm{CRH}$. All in all, this suggests that ELS in a sex-dependent manner may dysregulate HPA axis reactivity, which adds to the vulnerability to depression.

The above-mentioned evidence does not take into account that not every individual is equally sensitive to ELS; the latter is also determined by an individual's genetic background. This is particularly relevant for genes involved in HPA axis reactivity. One such protein is the mineralocorticoid receptor (MR), encoded by the gene Nr3c2. The MR binds corticosteroids (CORT) in the brain and is highly expressed in some limbic areas, e.g., in the hippocampus and medial prefrontal cortex (mPFC; Reul and de Kloet, 1985; Joëls et al., 2008). The MR is thought to exist in two forms: nuclear and membrane-associated; these can be functionally differentiated by their affinity for CORT (Kretz et al., 2001; Karst et al., 2005). The nuclear MR has a high affinity and is substantially activated even at the nadir of the circadian cycle. It mediates genomic and slow effects, which are involved in setting the threshold for HPA axis reactivity (Joëls et al., 2008). Conversely, the membrane-associated MR has a lower affinity for CORT, presumably lending it a role in the immediate (cognitive) response to stress (Joëls et al., 2015; Vogel et al., 2016). In order to adequately regulate the response to stress, MR works in close conjunction with the glucocorticoid receptor (GR; Reul and de Kloet, 1985; de Kloet et al., 2005).

Several MR single nucleotide variants (SNPs) have been described, each contributing to HPA axis regulation and the response to stress (van Leeuwen et al., 2010, 2011; DeRijk et al., 2011; Gerritsen et al., 2017). Two SNPs, rs2070951 (MR-2C/G; a C/G SNP) and rs5522 (MRI180V; an A/G SNP), were shown to be inherited in three common haplotypes, i.e., haplotype 1 (GA); haplotype 2 (CA) and haplotype 3 (CG; van Leeuwen et al., 2010). In vitro, haplotype 1 and 3 resulted in lower MR expression and transactivation capacity than haplotype 2 (van Leeuwen et al., 2011). MR expression and haplotypes are considered to be important in the vulnerability to stress-related psychopathology (DeRijk et al., 2011; ter Heegde et al., 2015; Joëls and de Kloet, 2017; Wingenfeld and Otte, 2019), in a sex-dependent manner. Thus, women carrying haplotype 1 or 3 , compared to those homozygous for haplotype 2, showed lower HPA and autonomic responses after experiencing a psychosocial stressor (van Leeuwen et al., 2011), higher stress scores (van Leeuwen et al., 2011), lower levels of optimism and higher levels of hopelessness (Klok et al., 2011; Hamstra et al., 2017) as well as a higher risk for depression (Klok et al., 2011). Of relevance, an ELS-by-sex-by-MR haplotype interaction was observed in a large sample of healthy individuals and a mixed healthy and clinical cohort. Thus, women exposed to ELS that carry haplotype 1 or 3 showed higher scores on a depression scale than women homozygous for haplotype 2, while this was not observed (or even the opposite) in males (Vinkers et al., 2015). Overall, this suggests that low MR function in females may exacerbate the influence of ELS on HPA axis reactivity and depression, while it might be protective in males.

This notion is not easy to test in a controlled and prospective manner in human cohorts. Therefore, we reverted to a mouse model to test the following hypotheses: first, ELS affects the HPA axis response to the acute stress of adult female mice differently than the response of males. Based on the human literature, we expect that adult female mice exposed to ELS are hypo-responsive to stress, while males exposed to ELS are hyperresponsive. Second, MR expression interacts with ELS effects 
in a sex-dependent manner; more specifically, we expect that down-regulation of MR causes exacerbation of ELS effects in females, while it serves a protective role in males.

To provoke ELS in a controlled manner, dams (and their litter) were housed in limited nesting and bedding conditions between postnatal day (P) 2 and 9 (Rice et al., 2008). We mimicked the conditions of MR haplotypes 1 and 3 (compared to haplotype 2) by decreasing MR expression, using a forebrainspecific heterozygous MR knock-out mouse, which includes the dorsal hippocampus and mPFC (Berger et al., 2006). In the adult male and female mice, we investigated several indices of HPA axis function, i.e., body weight and weight of stress-sensitive tissues including adrenals and thymus; circadian and stress-induced variations in CORT level; and MR and GR expression in the dorsal hippocampus and mPFC. In addition, we measured behavioral reactivity towards novelty and time spent in covered (as opposed to open) spaces, as a proxy for anxiety-like behavior.

\section{MATERIALS AND METHODS}

\section{Animals and Housing Conditions}

The current study was approved by the Animal Ethical Committee from Utrecht University, Netherlands. Every effort was taken to minimize animal suffering in accordance with the FELASA guidelines and the Dutch regulation for housing and care of laboratory animals (January 30th 2001/GZB/VVB 2148400). Experiments were performed blindly; animal distribution across experiments, as well as experimental order, was randomized. Experimental cages were randomly placed on the housing racks in stables with temperature $\left(22 \pm 2^{\circ} \mathrm{C}\right)$ and humidity ( $\sim 64 \%)$ control with reversed day-night cycle (light on 20:00-08:00). Standard chow pellets (Special Diet Services, UK) and tap water were provided ad libitum. Where possible, animals were socially housed with same sex and experimental littermates. Throughout all procedures, experimental manipulation and disturbances were kept to a minimum to avoid handling effects.

\section{Breeding of Experimental Animals}

For a detailed description of the mouse lines and breeding schedules, see Berger et al. (2006) and Knop et al. (2019). All experimental and breeding mouse lines were routinely maintained in the animal facility of the Department of Translational Neuroscience, UMC Utrecht Brain Center, Utrecht University to uphold a stable environment and prevent any stress that may otherwise be caused by transportation. Full forebrain-specific MR-knockout breeding males $\left(\mathrm{MR}_{\mathrm{CamKCre} / \mathrm{wt}}\right.$; $\mathrm{MR}_{\text {flox/flox }}$ ) were generated by crossing forebrain-specific CAMKII transgenic mice (purchased from the EMMA mouse repository) with $\mathrm{MR}_{\text {flox/flox }}$ female mice (loxP site flanked at $\mathrm{MR}$ exon 3; kindly provided by Dr. Stefan Berger).

For translational purposes, we modeled low rather than completely absent MR expression and therefore chose to study MR heterozygous knockout mice $\left(\mathrm{MR}_{\mathrm{CamKCre} / \mathrm{wt}} ; \mathrm{MR}_{\mathrm{flox} / \mathrm{wt}}\right)$ as an experimental model. To obtain this genotype in the offspring, one full knockout breeding male was paired with two in-house bred naive wildtype C57Bl/6JOlaHsd dams (10-12 weeks old; regularly purchased from Harlan, France); we preferred these wildtype females, to control for possible genetic differences in maternal care. The offspring consisted of heterozygous mice $\left(\mathrm{MR}_{\mathrm{CamKCre} / \mathrm{wt}} ; \mathrm{MR}_{\mathrm{flox} / \mathrm{wt}}\right)$ and litter-mate controls $\left(\mathrm{MR}_{\mathrm{wt} / \mathrm{wt}}\right.$; $\mathrm{MR}_{\text {flox/wt }}$ ), later referred to as $\mathrm{MR}_{\text {CamKCre/wt }}$ and $\mathrm{MR}_{\text {flox/wt }}$ for simplicity, respectively.

\section{Genotyping}

Genotyping was routinely performed on material obtained from ear-punching at weaning (PND21). DNA was isolated by degrading the material with $0.1 \mathrm{mg} / \mathrm{ml}$ Proteinase $\mathrm{K}$ in lysis buffer containing $1 \mathrm{M}$ Tris $\mathrm{pH}$ 8.0, 0.5 M EDTA $\mathrm{pH}$ 8.0, $10 \%$ SDS, $5 \mathrm{M} \mathrm{NaCl}$, and distilled water. Denaturation was performed by incubation of the material in a heat block for $60 \mathrm{~min}$ at $55^{\circ} \mathrm{C}$, then for $5 \mathrm{~min}$ at $105^{\circ} \mathrm{C}$ to eliminate Proteinase K. DNA was cleaned in Phenol:Chloroform:Isoamylalcohol (25:24:1), then in isopropanol. After $30 \mathrm{~min}$ spinning at $14,000 \mathrm{rpm}$, the obtained pellet was washed twice in 70\% Ethanol, then left to dissolve overnight.

The presence of CaMKIICre and $\mathrm{MR}_{\text {flox }}$ were verified by standardized routine PCR and Southern analysis procedures. Each sample was added in a concentration of $10 \%$ to a MasterMix containing $10 \%$ PCR buffer, $3 \% \mathrm{MgCl}_{2}, 10 \% \mathrm{dNTP}, 2.5 \% \mathrm{Taq}$ polymerase, $5 \%$ of each primer, and distilled water. The following primers were obtained from the Berger lab (Berger et al., 2006): For $\mathrm{MR}_{\text {flox }}$ :

Primer A (MRflox-10): 5'-CTGAAGTCACTGGCTAG AGTC-3';

Primer B (MR flox -11): 5' -CCAGCCTCTGAGCCCAGAAAG-3'; Primer C ( $\left.\mathrm{MR}_{\mathrm{flox}}-12\right): 5^{\prime}$-GTCCCATCTTGCTTACCCTGA-3'. For CamKCre:

Primer A (CAMK-13):5'-GGTTCTCCGTTTGCACTCAG GA-3';

Primer B (CAMK-14): 5' -CCTGTTGTTCAGCTTGCAsCCA-3'; Primer C (CAMK-15): 5'-CTGCATGCACGGGACAGCTCT-3'.

Amplification consisted of 35 cycles, from 63 to $72^{\circ} \mathrm{C}$. After amplification of the target genes, the samples were loaded with $6 \times$ loading buffer on $3 \%$ agarose gel, and run for $30 \mathrm{~min}$ at $100 \mathrm{~V}$. Positive bands at $345 \mathrm{bp}$ for CaMKcre, and $335 \mathrm{bp}$ for $\mathrm{MR}_{\mathrm{flox}}$ indicated a presence of the genes.

\section{Early Life Stress Paradigm}

ELS was elicited via the limited nesting and bedding method, previously adapted to mice by Rice et al. (2008). This model induces chronic stress early in life by means of fragmented and unpredictable maternal behavior, thus affecting the quality but not the quantity of maternal care. Briefly, 1 week before the expected date of birth, dams were individually housed in type II short Macrolon cage with a filter top and provided with a cotton Nestlet $(5 \times 5 \mathrm{~cm}$, Technilab-BMI, Someren, Netherlands) as nesting material. Around the expected delivery day, cages were checked twice daily for litters. If a new litter was found before $10.00 \mathrm{AM}$, the previous day was assigned as the date of birth (PND0). Each experimental cage was randomly allocated to either the ELS or control condition. In the morning of P2 (between 09.00 and 10.00 AM), the litters were culled to six pups with approximate equal sex ratio. Litters with pups from the 
same sex were excluded $(n=1)$. Pups were weighed and housed in either the ELS or control condition in a new polycarbonate type II short cage $\left(268 \times 215 \times 261 \mathrm{~mm}\right.$, Techniplast $\left.{ }^{\mathrm{TM}}\right)$. Control cages were equipped with standard amounts of sawdust bedding and one cotton Nestlet for nesting material $(5 \times 5 \mathrm{~cm}$; Technilab-BMI, Someren, Netherlands). In the ELS cages, the floor was covered with a little amount of sawdust bedding and was fitted with a fine-gauge stainless steel grid (Naninck et al., 2015). ELS litters were provided with half a piece of Nestlet $(2.5 \times 5 \mathrm{~cm})$ as nesting material. All cages were covered with a filtertop and left undisturbed for 7 days. On P9, pups were weighed and moved with the dam to standard housing cages. In a pilot [control $(n=10)$ vs. ELS pups $(n=11)$ ], body weight gain (4.24 \pm 0.19 vs. $1.82 \pm 0.18$ g; $p<0.001)$, thymus (but not adrenal) weight $(0.68 \pm 0.03$ vs. $0.34 \pm 0.05$; $p<0.001$ and $0.03 \pm 0.01$ vs. $0.03 \pm 0.01 ; p=0.46$ for both corrected thymus and adrenal weights) as well as corticosterone levels $(3.80 \pm 1.14$ vs. $13.86 \pm 0.93 \mathrm{ng} / \mathrm{ml} ; p<0.001)$ in the offspring were significantly changed at $\mathrm{P} 9$, in accordance with earlier reports (Rice et al., 2008; Naninck et al., 2015). In the remained of the study we used body weight on P9 as a proxy of the effects induced by the model.

After weaning (P21), mice were ear-punched for identification and genotyping, then reallocated and housed per experimental condition in sex-specific rooms with similar housing conditions in type II L cages $(365 \times 207 \times 140 \mathrm{~mm}$, Tecniplast ${ }^{\mathrm{TM}}$ ) until the time of testing in adulthood (10-12 weeks of age). The cohorts that were used for acute restraint stress and protein analysis were socially housed with littermates. The cohort that was used for the behavioral analysis was also group-housed up to the moment that they were individually placed in the home cages i.e., the experimental condition of interest.

\section{Effect of ELS and MR on Circadian HPA Axis Activity}

To assess circadian peak and nadir corticosterone levels, we sampled adult male and female $\mathrm{MR}_{\mathrm{CamKCre} / \mathrm{wt}}$ and $\mathrm{MR}_{\text {flox/wt }}$ mice ( $n=11$ per condition per sex per genotype), previously exposed to control or ELS condition. Blood samples were collected via tail nick, approximately 30-60 min before the light switch (20.00 and $08.00 \mathrm{~h}$ ). In order to evaluate changes in CORT levels as a measure of circadian HPA axis activity, differences between groups were first analyzed with a $2 \times 2$ repeated-measures design (for the factor time), in which condition and sex were the independent variables. Next, we tested hypothesisdriven whether MR genotype would exacerbate the findings specifically in the ELS groups which was analyzed using a $t$-test with Holm's correction. Missing samples were roughly equally distributed over all groups and accounted for $4 \%$ in males and $5.5 \%$ in females.

To determine corticosterone plasma levels, blood samples were processed as described before (Sarabdjitsingh et al., 2010). Briefly, samples were centrifuged at $13,200 \mathrm{rpm}$ for $10 \mathrm{~min}$ at $4^{\circ} \mathrm{C}$. Plasma was isolated and stored at $-20^{\circ} \mathrm{C}$ until further use. Plasma CORT levels were determined by using a commercially available radioimmunoassay (RIA) kit (ImmuChemTM Double Antibody, MR Biomedicals, Inc.) according to the manufacturer's instructions. Samples were counted in duplicate and processed within the same run to avoid inter-assay variation.

\section{Effect of ELS and MR on Stress-Induced HPA Axis Activity}

Acute HPA axis reactivity to restraint stress was expressed absolutely to the baseline blood sample collected the previous day at the nadir when CORT levels are lowest. The next day, mice were placed for $10 \mathrm{~min}(t=0$ starting time) in a cylindrical plexiglass restraint tube (diameter $=6 \mathrm{~cm}$ ) furnished with breathing holes, then placed solitarily in new cages enriched with bedding material of their old cage to avert novelty-induced stress. For evaluation of the stress-mediated release of CORT, blood samples via tail nick were taken at 10-min intervals from stress onset $(t=10, t=20, t=30)$. Blood was collected via tail nick in Microvette ${ }^{\circledR}$ tubes (200LH, Sarstedt AG \& Co), and never exceeded $20 \mu \mathrm{L}$ per measurement per animal. The time of first handling of the animal to finish sampling was as fast as possible and never exceeded $2 \mathrm{~min}$. At $t=60$, the animals were decapitated and trunk blood was collected in tubes (16 I.U. Heparin, Sarstedt AG \& Co) containing one granule of heparin to prevent coagulation. HPA axis reactivity was evaluated by testing whether ELS and/or sex affected changes in plasma CORT level over time across groups. Additionally, adrenal glands, thymi and spleens were rapidly dissected and stored at $4^{\circ} \mathrm{C}$ for a maximum of $3 \mathrm{~h}$ before being routinely cleaned and weighted. Body weights of all experimental animals were recorded the day prior to their respective experiment when baseline blood samples were collected. Organ weights were analyzed as a percentage of body weight for each animal.

Results were first analyzed with a $2 \times 2$ (sex*ELS-condition; repeated measures) ANOVA. If applicable, the secondary analysis was performed with a $t$-test (Holm's correction for multiple comparisons) for MR genotype in subgroups that were exposed to ELS for each sex separately.

\section{Effect of ELS and MR on Corticosteroid Receptor Expression in the Brain}

The effects of ELS* sex and the potential effect of MR background on MR and GR levels in limbic brain regions were studied by (semi-quantitatively) measuring protein expression with Western blot analysis.

\section{Tissue Collection and Sample Preparation}

Adult male and female mice (week 10-12) were sacrificed via rapid decapitation between 9.30 and 10.30 AM. Dorsal hippocampus (upper third of the hippocampus on the dorsal side) and $\mathrm{mPFC}$ of both hemispheres were collected using a stainless-steel brain matrix (RBMA-200C, World Precision Instruments). Hippocampal and mPFC tissues were immediately processed into purified protein, in an RNase-free environment by use of RNaseZAP on all materials (Sigma-Aldrich). Pilot experiments in which we collected amygdala tissue with the use of micro-punches revealed that the amount of tissue collected in this manner was too low to allow reliable Western blot measurements. 
As previously described (Sarabdjitsingh et al., 2010; Loi et al., 2015), the samples were homogenized using a homogenizer (IKA ${ }^{\circledR}$ T10 basic) with ice-cold lysis buffer (RIPA) containing $1 \mathrm{M}$ Tris, $1 \mathrm{M} \mathrm{NaCl}, 0.5 \%$ sodium deoxycholate, $0.1 \%$ SDS, $1 \%$ Triton, and $1 \mathrm{mM}$ EDTA of $\mathrm{pH}$. The samples were clarified by centrifugation for $20 \mathrm{~min}$ at $13,200 \mathrm{rpm}$ at $4^{\circ} \mathrm{C}$, then aliquoted and stored at $-80^{\circ} \mathrm{C}$ for further use.

\section{Western Blot Analysis}

Protein concentrations were calculated with the slope of a BSA-derived standard curve, by running samples in duplicate with a BCA kit (Pierce, ThermoFisher) in a microplate reader (Varioskan Flash, Thermo Scientific). Approximate equal amounts (15 $\mu \mathrm{g}$ for hippocampal samples, and $17 \mu \mathrm{g}$ for mPFC) of protein denaturated at $95^{\circ} \mathrm{C}$ for 5 min were separated on a $10 \%$ SDS-polyacrylamide gel $(25 \mathrm{~mA}$ in stacking gel, $30 \mathrm{~mA}$ in resolving gel) and electro-transferred $(100 \mathrm{~V}, 1 \mathrm{~h})$ onto a nitrocellulose membrane $(0.45 \mu \mathrm{m}$ thickness, GE Healthcare Life Sciences, Amsterdam). To reduce unspecific binding, 5\% non-fat milk powder (Elk, Campina) in Tris-buffered saline (TBS) was used as blocker for $1 \mathrm{~h}$ at room temperature on a shaker. Primary antibody incubation diluted in TBS 1\% Tween20 (TBS-T) lasted $3 \times$ overnight with mouse monoclonal primary antibody anti-MR (rMR1-18 1D526, dilution 1:500; Gomez-Sanchez et al., 2006), and $1 \times$ overnight with rabbit polyclonal antibody anti-GR [GR(M-20), 1:1,000, sc-1004, Santa Cruz Biotechnology Inc., Santa Cruz, CA, USA]. Rabbit polyclonal anti-GAPDH (GAPDH 14C10, 1:3,000, Cell Signalling Technology ${ }^{\circledR}$ Inc., Santa Cruz, CA, USA) was used in both cases as a control protein for standardization. After incubation, membranes were washed $3 \times$ for $10 \mathrm{~min}$ at room temperature with TBS-T, then incubated with the secondary antibodies diluted in $2 \%$ milk TBS-T for $1 \mathrm{~h}$ at room temperature. The secondary antibodies used were goatanti-mouse (1:30,000, Molecular Probes, Eugene, OR, USA) and goat-anti-rabbit $(1: 50,000)$ for MR and GR/GAPDH respectively. After washing membranes $3 \times$ for $10 \mathrm{~min}$ in TBS-T, the proteins were detected using peroxide for chemiluminescent detection of horseradish peroxidase (SuperSignal ${ }^{\mathrm{TM}}$ West Dura, Thermo Scientific), and visualized by FluorChemE (proteinsimple ${ }^{\mathrm{TM}}$, Westburg). Membranes were then stripped for $5 \mathrm{~min}$ at $60^{\circ} \mathrm{C}$ with stripping buffer composed of $25 \%$ Tris, $0.7 \% \beta$ mercaptoethanol, $2 \%$ SDS, and distilled water. After $3 \times 5$ min washing with TBS, the same procedure from the blocking step was used for the GR protein.

The loading scheme was randomized, yet each membrane had equal samples per group. In line with previous research, GR and GAPDH were represented on the blots by one line each, respectively at $\sim 90 \mathrm{kDa}$ and $\sim 37 \mathrm{kDa}$. Conversely, MR displayed two bands at $\sim 130 \mathrm{kDa}$, thus $\sim 20 \mathrm{kDa}$ heavier than expected. Nevertheless, these bands were confirmed to be the protein of interest as technically validated with samples from full MR knockout mice (Figure 1). The difference in molecular weights is presumably due to posttranslational modifications. The two MR bands were correlated at 0.93; thus only the upper one was quantified. Bands were quantified with ImageJ, corrected for background, standardized with GAPDH, and normalized to $\mathrm{MR}_{\mathrm{flox} / \mathrm{wt}}$ control. Each sample was blotted twice (technical

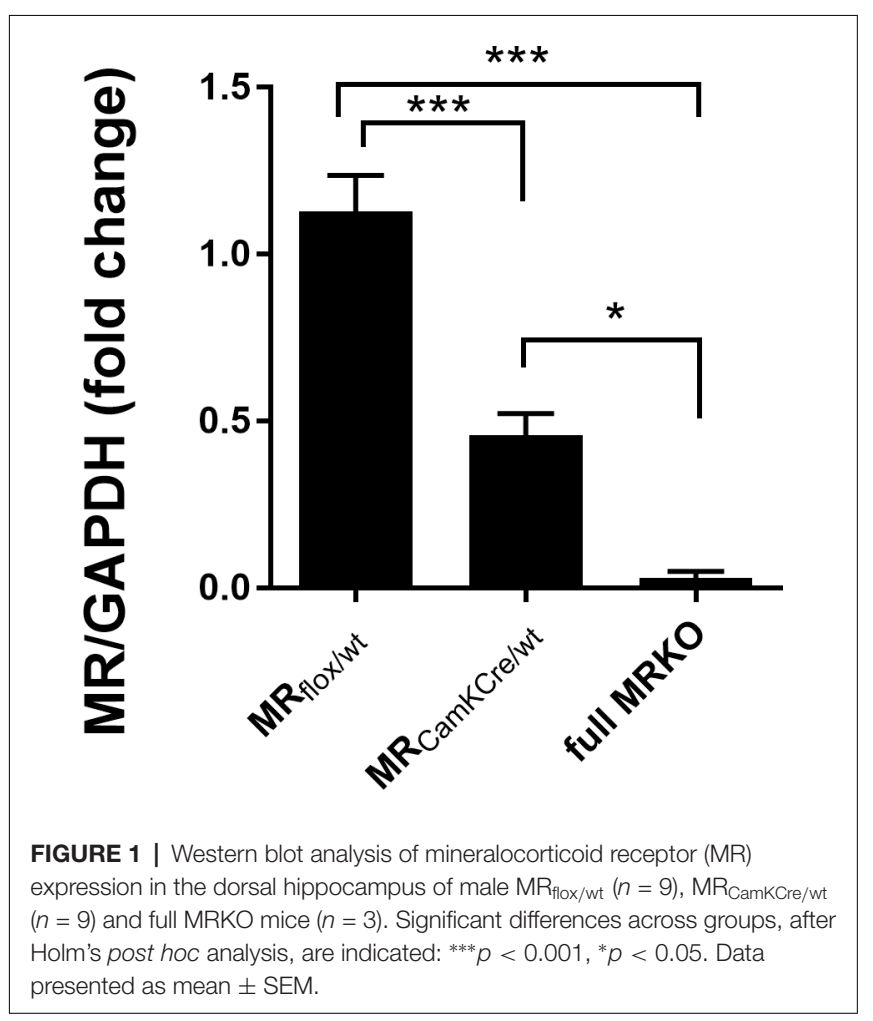

replicates), and the results were then pooled together as mean per animal after normalization.

\section{Effect of ELS and MR on Novelty-Induced Behavioral Reactivity}

We used exposure to a novel environment as a means to study putative changes in stress-induced behavior. We selected novelty-induced behavior because $\mathrm{MR}$ is known to modulate the behavioral response to novelty (Berger et al., 2006; Brinks et al., 2009; ter Horst et al., 2012; Arp et al., 2014). A second batch of mice was solitarily placed for a period of $7 \mathrm{~h}$ (one time point per hour) in a "home cage," an automated system for behavior and location tracking, here used to assess noveltyinduced activity (Kas et al., 2008; Molenhuis et al., 2014). The home cage apparatus $[30 \times 30 \times 35$ (length $\times$ width $\times$ height) $]$ was built at the University Medical Center Utrecht (NL), and it consists of a home base shelter $(10.8 \times 6.3 \times 6.4 \mathrm{~cm})$, and two ad libitum feeding platforms $(6.3 \times 5.8 \times 10.5 \mathrm{~cm})$ of which one is protected and one which is not. The remaining space is furnished with a liter of sawdust and a drinking bottle with tap water (Kas et al., 2008).

Rodent behavior was monitored using the automated videobased observation system PhenoTyper (Noldus Information Technology, Wageningen). The video tracking was performed at a rate of 12.5 samples/s with a spatial resolution of approximately $0.6 \mathrm{~mm}$. Movement was defined as such when start velocity exceeded $2 \mathrm{~cm} / \mathrm{s}$ and stop velocity exceeded $1.75 \mathrm{~cm} / \mathrm{s}$, thus excluding grooming and licking. The data were then extracted with software EthoVision 3.0, which provided mean values per time point requested. 
Locomotor activity (proxy for anxiety-like behavior, exploration and strategy) was operationalized as the linear combination of distance moved, time spent moving and velocity. The correlations between these variables did not exceed 0.63. Information about each of these parameters separately is available in our online data files. Due to tracking mistakes, about $1 \%$ of values were missing. Additionally, $1.5 \%$ of data points were considered as outliers, being outside the 2.5 standard deviation (SD) interval, including in three animals which were outliers in every variable; presumably, these were mostly due to tracking problems. Missing values were randomly distributed across variables and groups.

\section{Statistical Analysis}

Data are presented as mean \pm SEM. The analysis was conducted in two stages. First, we tested whether ELS differentially affects males and females in stress-related outcomes by using $2 \times 2$ (sex*condition) ANOVAs. Second, if post hoc tests were significant, we tested whether $\mathrm{MR}_{\mathrm{CamKC} \text { re/wt }}$ genotype enhanced the effects. At this purpose, we compared genotypes in animals with a history of ELS, separately for males and females. This approach was chosen with the intent to limit statistical testing, while still answering primary research questions. Main effects are reported in the text while statistically significant post hoc effects are also graphically indicated with symbols.

Post hoc analyses were conducted with Holm's correction for multiple comparisons. Missing values were imputed with a single imputation method, which was repeated five times to verify the sensitivity of the results (van Buuren and GroothuisOudshoorn, 2011). Huynh-Feldt correction was used to correct for the departure from sphericity. Concerning AN(C)OVAs' sum of squares, type III and type II were used, respectively when interaction effects were present or absent. Slopes were calculated as best-fitting. The trapezoid rule was used to calculate the area under the curve. The analysis was conducted in the computer program R (version 3.2.3; Team, 2015), with the aid of the following R packages: (1) "mice" for imputation (van Buuren and Groothuis-Oudshoorn, 2011); and (2) "car" for AN(C)OVAs (Fox and Weisberg, 2011). Statistical significance was assigned at $p<0.05$.

\section{RESULTS}

\section{Validation of the Experimental Model}

\section{MR Expression in the MR $\mathrm{M}_{\text {CamkCre/wt }}$ Is Reduced by $\sim 50 \%$}

We used a genetic mouse model to experimentally alter forebrain-specific MR protein levels (Berger et al., 2006). The heterozygous MR mouse is expected to have a $50 \%$ reduction of MR protein in limbic brain areas. To test this, MR expression was assessed in a separate batch of male animals $(n=9)$ with western blot analysis in the dorsal hippocampus of adult mice (Figure 1). Compared to $\mathrm{MR}_{\text {flox/wt }}$ controls, $\mathrm{MR}$ expression in the $\mathrm{MR}_{\mathrm{CamKCre} / \mathrm{wt}}$ mice was indeed reduced by $51 \%$ $\left(F_{(2,16)}=29,52 ; p<0.001\right.$; post hoc comparison $\left.p<0.001\right)$. As a reference, MR protein was completely absent in the full knockout $\mathrm{MR}_{\text {CamKCre }}$ mice. These results confirm that MR expression in the heterozygous mice is indeed reduced in the limbic brain and can be used as a suitable model to study decreased receptor levels in the limbic brain.

\section{ELS Effectively Decreases Body Weight Gain at P9 in Both Males and Females}

To validate the effectiveness of the ELS paradigm, we monitored body weights of the pups at the beginning (P2) and end (P9) of the experimental condition, a measure commonly affected by stress (Rice et al., 2008; Naninck et al., 2015). At the onset of the model (P2), there were no differences in body weight linked to assigned ELS condition or sex (Figure 2A). A week later at P9, ELS pups had significantly lowered body weight when compared to controls (Figure 2B; main effect of condition $F_{(1,44)}=89.45$; $p<0.001$ ), yet comparable between males and females (main effect of sex $\left.F_{(1,44)}=0.03 ; p=0.87\right)$. The MR genotype was unknown at this stage and could therefore not be tested.

\section{ELS-Induced Decrease in Body Weight Only Persists in Adult Females}

In adulthood, all animals were weighted again to study whether the ELS-induced reduction in body weight would persist (Figure 3). We first analyzed and confirmed a sex*condition effect $\left(F_{(1,85)}=58.3 ; p<0.05\right)$. Post hoc analysis showed that the ELS-induced reduction in body weight only persisted in females $(p<0.05)$.

Next, we hypothesized that this ELS-induced reduction in body weight in females was exacerbated by low expression of $\mathrm{MR}$, comparing $\mathrm{MR}_{\text {flox/wt }}$ to $\mathrm{MR}_{\text {CamKCre/wt }}$ females after ELS. This difference was however not significantly different $\left(t_{(13,8)}=1.72\right.$; $p=0.11$ ). All summary statistics are provided in Table $\mathbf{1}$.

\section{Indices of HPA Axis Under Unstressed, Baseline Conditions in Adulthood}

\section{Weight of Stress-Sensitive Tissues}

We routinely monitored weight of stress sensitive tissues as markers of HPA axis activity, i.e., adrenals, thymus and spleen (Table 1); notably, these values are indicative for both basal and stress-induced conditions. We did not find any significant interaction effect for sex*condition for either thymus $\left(F_{(1,84)}=1.63 ; p=0.21\right)$, adrenal $\left(F_{(1,84)}=2.85 ; p=0.10\right)$ or spleen weight $\left(F_{(1,84)}=0.49 ; p=0.49\right)$.

\section{Circadian Variation in Corticosterone Levels}

Peak and nadir corticosterone levels were assessed in all experimental groups to study the HPA axis under unstressed condition (Figure 4). All groups displayed typical circadian differences in steroid levels with higher corticosterone concentrations during the peak compared to the nadir (main effect of time $F_{(1,85)}=54.74 ; p<0.001$ ). Additionally, sex-differences in corticosterone levels were also confirmed (main effect of $\operatorname{sex}\left(F_{(1,85)}=12.51 ; p<0.001\right)$, with females having higher average circulating corticosterone levels. ELS did not interact with sex (interaction effect: $F_{(1,85)}=2.82 ; p=0.1$ ).

Altogether, these results suggest that none of the indices for baseline (unstressed) HPA axis activity is affected by ELS in either males or females. 

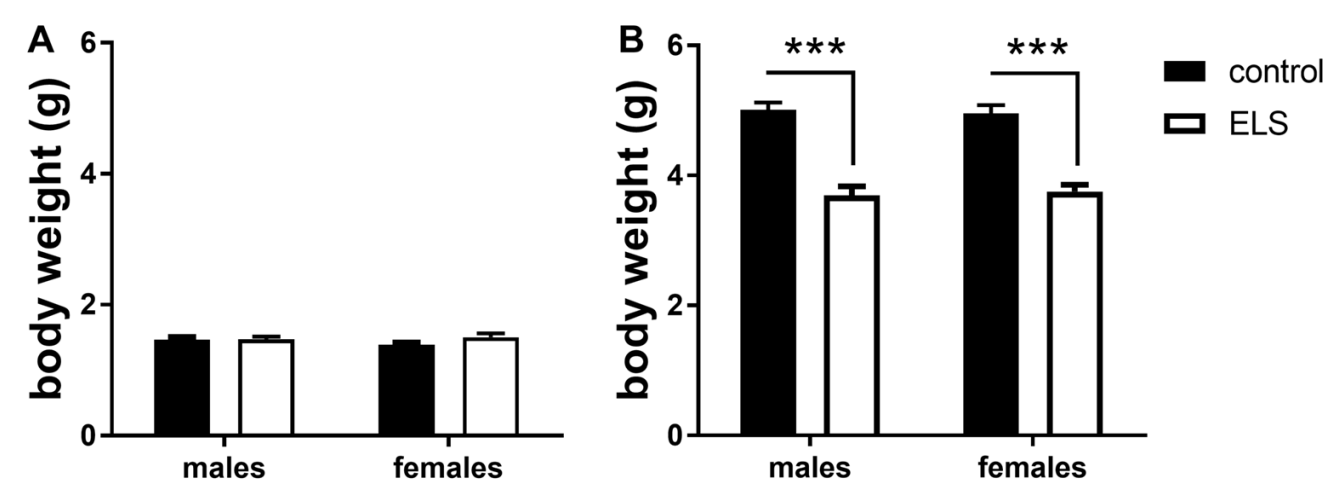

FIGURE 2 | Averaged body weight ( $($ SEM) of the pups in experimental litters (A) at the start (P2; B) and end (P9) for control (black bars) and early life stress (ELS) condition (open bars). Mean weight per litter was calculated for both males and females. Data were analyzed with averaged litter size at P2 as covariate for the analysis of body weight at P9. Significance indicates main effect of ELS $\left(F_{(1,44)}=89.45, p<00.001\right),{ }^{* * *} p<0.001$.

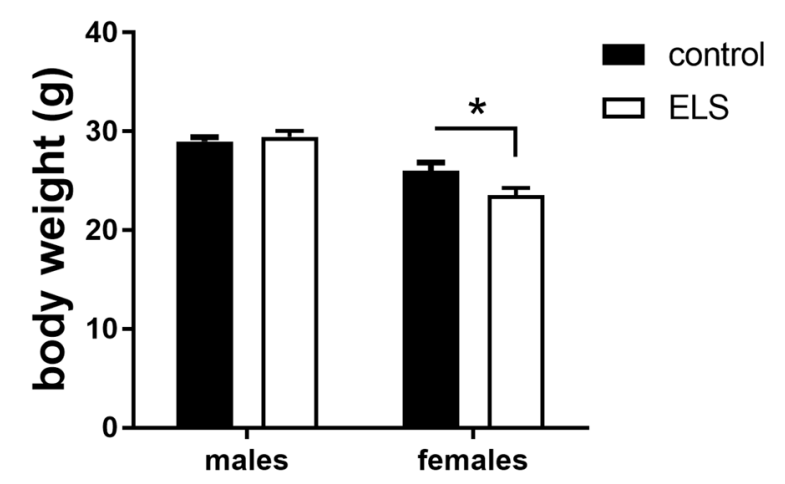

FIGURE 3 | Averaged body weight ( \pm SEM) of adult control (black bars) and ELS animals (open bars). Mean weight per group ( \pm SEM) was calculated for both males and females. Significant differences between groups using a $t$-test with Holm's correction are indicated, ${ }^{*} p<0.05$.

\section{HPA Axis Function Under Acute Stress Conditions in Adulthood}

\section{Stress-Induced HPA Axis Reactivity}

To investigate HPA axis reactivity to stress, mice were immobilized in a restrainer for $10 \mathrm{~min}$, and plasma corticosterone levels were assessed at different time intervals from onset (Figure 5). We used a repeated-measures analysis to test sex*ELS condition differences in corticosterone levels over time.

Overall, immobilization stress effectively increased corticosterone levels in all experimental groups (Figure $\mathbf{5 A}$; main effect of time $\left.F_{(4,332)}=113.73 ; p<0.001\right)$. Females had overall higher averaged corticosterone levels than males (main effect of sex $F_{(1,83)}=77.90 ; p<0.001$ ). As hypothesized, ELS effects had opposing directionality in males compared to females (interaction effect sex*ELS condition $F_{(1,83)}=10.64$; $p<0.01)$. Post hoc analysis indicated that in males a history of ELS marginally increased stress-induced corticosterone levels, although this was only at trend level $(p=0.07)$. Conversely, in females, a history of ELS strongly attenuated the response to restraint stress (Figure 5A; $p=0.01$ ).

Next, we tested whether the ELS-induced reduction in stress reactivity in females was exacerbated by MR genotype. Post hoc analysis indicated that under ELS conditions in females, the $\mathrm{MR}_{\mathrm{CamKCre} / \mathrm{wt}}$ indeed further decreased corticosterone levels compared to the $\mathrm{MR}_{\text {flox/wt }}$ controls (Figure 5B; $p<0.01$ ).

\section{Adult MR and GR Expression}

We evaluated the effect of ELS and/or MR genotype on MR and GR expression in the dorsal hippocampus and MPFC given their prominent role in the stress circuitry (Jankord and Herman, 2008). All results are described in Table 2. Representative images of the western blot of dorsal hippocampus samples are provided in Figure 6.

ELS affected MR expression in the dorsal hippocampus in a significantly different manner in males compared to females (interaction effect $\left.F_{(1,55)}=5.15 ; p<0.05\right)$. Post hoc analysis showed that in males ELS significantly increased MR expression $(p<0.01)$ which was normalized by the $\mathrm{MR}_{\mathrm{CamKCre} / \text { wt }}$ genotype $(p<0.01)$. This effect was not found in mPFC (sex*ELS condition effect $F_{(1,56)}=0.05 ; p=0.83$ ). MR expression levels in females were not affected by ELS in either the hippocampus nor $\mathrm{MPFC}$.

Additionally, ELS significantly affected hippocampal GR expression in both sexes (interaction effect sex*ELS condition $\left.F_{(1,55)}=4.34 ; p<0.05\right)$. However, post hoc analysis showed that only a trend towards increase was observed in males $(p=0.07)$ and not in females $(p=0.26)$. There was no interaction effect in GR expression levels in $\operatorname{mPFC}\left(F_{(1,56)}=0.59 ; p=0.45\right)$.

\section{Behavioral Reactivity to Novelty}

We assessed behavioral reactivity to a novel environment $(7 \mathrm{~h})$ and place preference for a sheltered space in automated home cages, the latter as a proxy for anxiety.

\section{Novelty-Induced Locomotor Activity}

Locomotor activity was operationalized as a composite score of distance moved, velocity and amount of time spent moving, in response to exposure to a novel environment (Figure 7). 

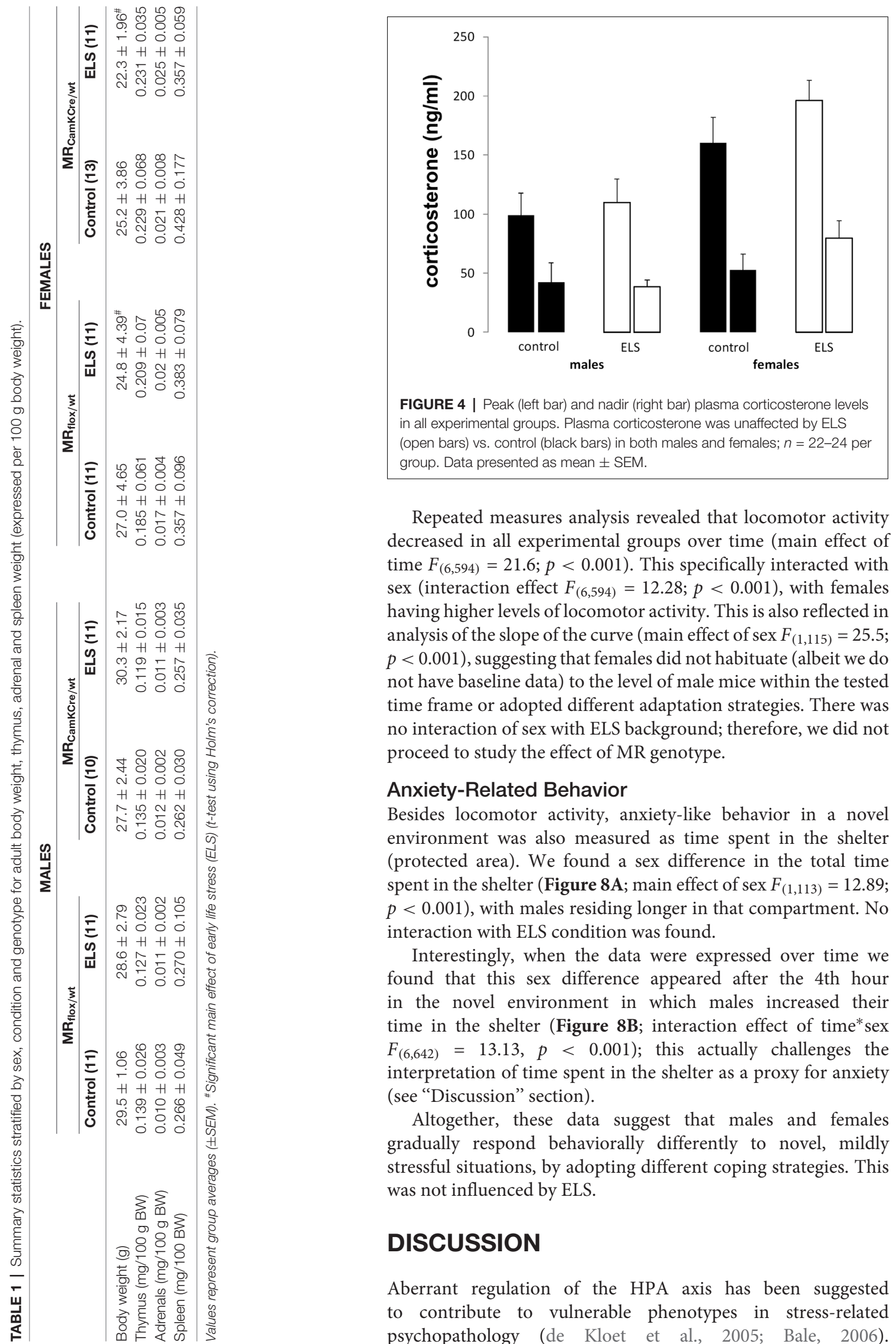

Repeated measures analysis revealed that locomotor activity decreased in all experimental groups over time (main effect of time $\left.F_{(6,594)}=21.6 ; p<0.001\right)$. This specifically interacted with sex (interaction effect $F_{(6,594)}=12.28 ; p<0.001$ ), with females having higher levels of locomotor activity. This is also reflected in analysis of the slope of the curve (main effect of $\operatorname{sex} F_{(1,115)}=25.5$; $p<0.001$ ), suggesting that females did not habituate (albeit we do not have baseline data) to the level of male mice within the tested time frame or adopted different adaptation strategies. There was no interaction of sex with ELS background; therefore, we did not proceed to study the effect of MR genotype.

\section{Anxiety-Related Behavior}

Besides locomotor activity, anxiety-like behavior in a novel environment was also measured as time spent in the shelter (protected area). We found a sex difference in the total time spent in the shelter (Figure 8A; main effect of $\operatorname{sex} F_{(1,113)}=12.89$; $p<0.001$ ), with males residing longer in that compartment. No interaction with ELS condition was found.

Interestingly, when the data were expressed over time we found that this sex difference appeared after the 4th hour in the novel environment in which males increased their time in the shelter (Figure 8B; interaction effect of time*sex $\left.F_{(6,642)}=13.13, p<0.001\right)$; this actually challenges the interpretation of time spent in the shelter as a proxy for anxiety (see "Discussion" section).

Altogether, these data suggest that males and females gradually respond behaviorally differently to novel, mildly stressful situations, by adopting different coping strategies. This was not influenced by ELS.

\section{DISCUSSION}

Aberrant regulation of the HPA axis has been suggested to contribute to vulnerable phenotypes in stress-related psychopathology (de Kloet et al., 2005; Bale, 2006). 

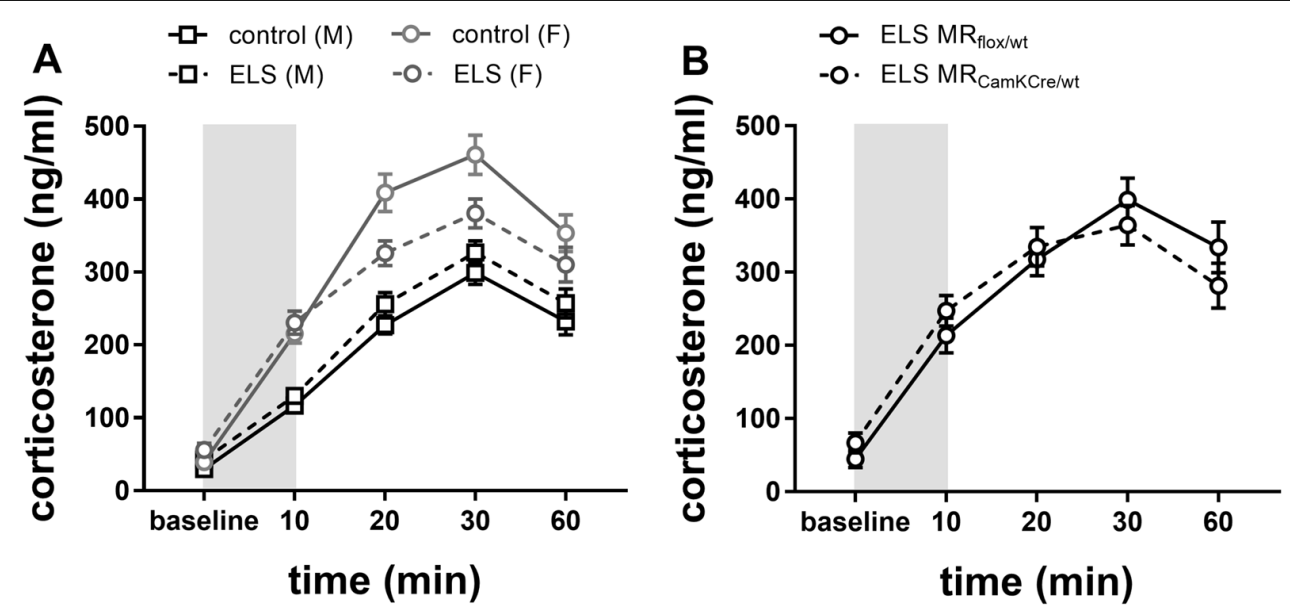

FIGURE 5 | (A) Plasma corticosterone levels after immobilization (10 min restraint stress) were analyzed using repeated measures over time in control males and females (black and gray solid line) or in ELS males and females (black and gray dotted line; $n=22-24$ per group). Data presented as mean \pm SEM. (B) Plasma corticosterone levels after immobilization plotted for genotype in the females exposed to ELS ( $n=9-11$ per group). Data presented as mean \pm SEM.

TABLE 2 | Analysis of Western blot experiments of mineralocorticoid receptor (MR) and glucocorticoid receptor (GR) protein levels in dorsal hippocampus and medial prefrontal cortex (MPFC).

\begin{tabular}{|c|c|c|c|c|c|c|c|c|}
\hline \multirow[b]{3}{*}{$\mathrm{HC}$} & \multicolumn{4}{|c|}{ MALES } & \multicolumn{4}{|c|}{ FEMALES } \\
\hline & \multicolumn{2}{|c|}{$\mathrm{MR}_{\text {flox } / \mathrm{wt}}$} & \multicolumn{2}{|c|}{ MR $_{\text {CamKCre/wt }}$} & \multicolumn{2}{|c|}{$\mathrm{MR}_{\text {flox } / \mathrm{wt}}$} & \multicolumn{2}{|c|}{ MR $_{\text {CamKCre/wt }}$} \\
\hline & Control & ELS & Control & ELS & Control & ELS & Control & ELS \\
\hline MR & $1.00 \pm 0.03(9)$ & $1.79 \pm 0.15(8)^{\#}$ & $0.50 \pm 0.09(9)$ & $0.97 \pm 0.08(8)^{\# @ ~}$ & @ $1.00 \pm 0.09(6)$ & $1.06 \pm 0.14(5)$ & $0.64 \pm 0.07(6)$ & $0.68 \pm 0.08(6)$ \\
\hline mPFC & Control & ELS & Control & ELS & Control & ELS & Control & ELS \\
\hline MR & $1.00 \pm 0.07(9)$ & $1.59 \pm 0.20(8)$ & $0.53 \pm 0.08(9)$ & $0.85 \pm 0.14(8)$ & $1.00 \pm 0.16(6)$ & $0.95 \pm 0.19(6)$ & $0.46 \pm 0.03(6)$ & $0.37 \pm 0.07(6)$ \\
\hline
\end{tabular}

Values indicate normalized group averages (ISEM). " Significant main effect of ELS (t-test using Holm's correction). ${ }^{\circledR}$ Significant effect of MR genotype in ELS groups: MR flox/wt vs. MR CamkCre/wt (t-test using Holm's correction).

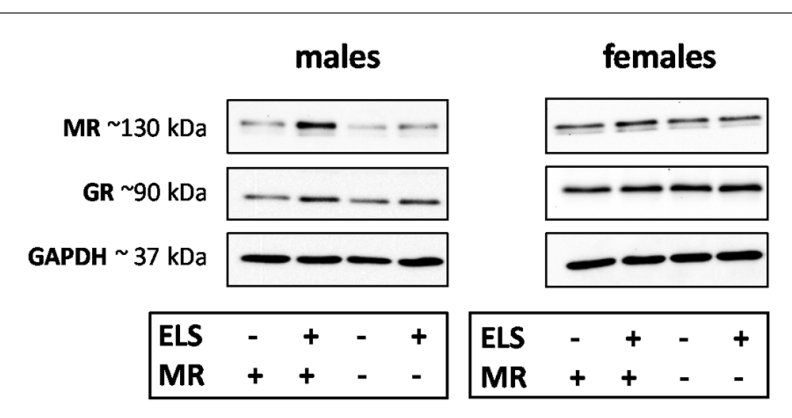

FIGURE 6 | Representative images of MR, glucocorticoid receptor (GR) and GAPDH western blots in male and female samples of the dorsal hippocampus ( $n=5-9$ per experimental group). The results of the medial prefrontal cortex (mPFC) were highly comparable. Legends in the graph: ELS $(-$ or +$)$ refers to either control or ELS condition; MR $(-$ or +$)$ refers to the $\mathrm{MR}_{\text {flox } / \mathrm{wt}}$ or $\mathrm{MR}_{\text {CamkCre/wt }}$.

This is supposedly caused by an interplay between genetic predisposition and environmental challenges (Claessens et al., 2011; Daskalakis et al., 2013), of which the sequence of events is still largely unknown. To follow this in a prospective manner, the current study aimed to tie together recently identified factors in psychopathology and the mediating role of HPA axis functioning: (i) sex-dependent effects of ELS; and (ii) a putative modulation by the MR (Heim et al., 2008; Strüber et al., 2014; ter Heegde et al., 2015; Joëls and de Kloet, 2017). We specifically focused on the role of the $M R$, in view of recent evidence supporting that some MR haplotypes confer resilience to depression in a sex-dependent manner (Vinkers et al., 2015); this does not negate that variants of the GR gene may also contribute to the vulnerability to develop psychopathology in the face of early life events (e.g., Sarubin et al., 2017).

We report four main findings: (i) indices of HPA axis activity under non-stressed conditions are different between males and females but are not affected by ELS; (ii) immobilization stress induced opposing ELS-specific effects, with increased corticosterone levels in males but decreased in females. In females, low MR expression levels exacerbated this effect; (iii) in males but not females, ELS increased MR expression in dorsal hippocampus and MPFC in male mice; and (iv) when exposed 

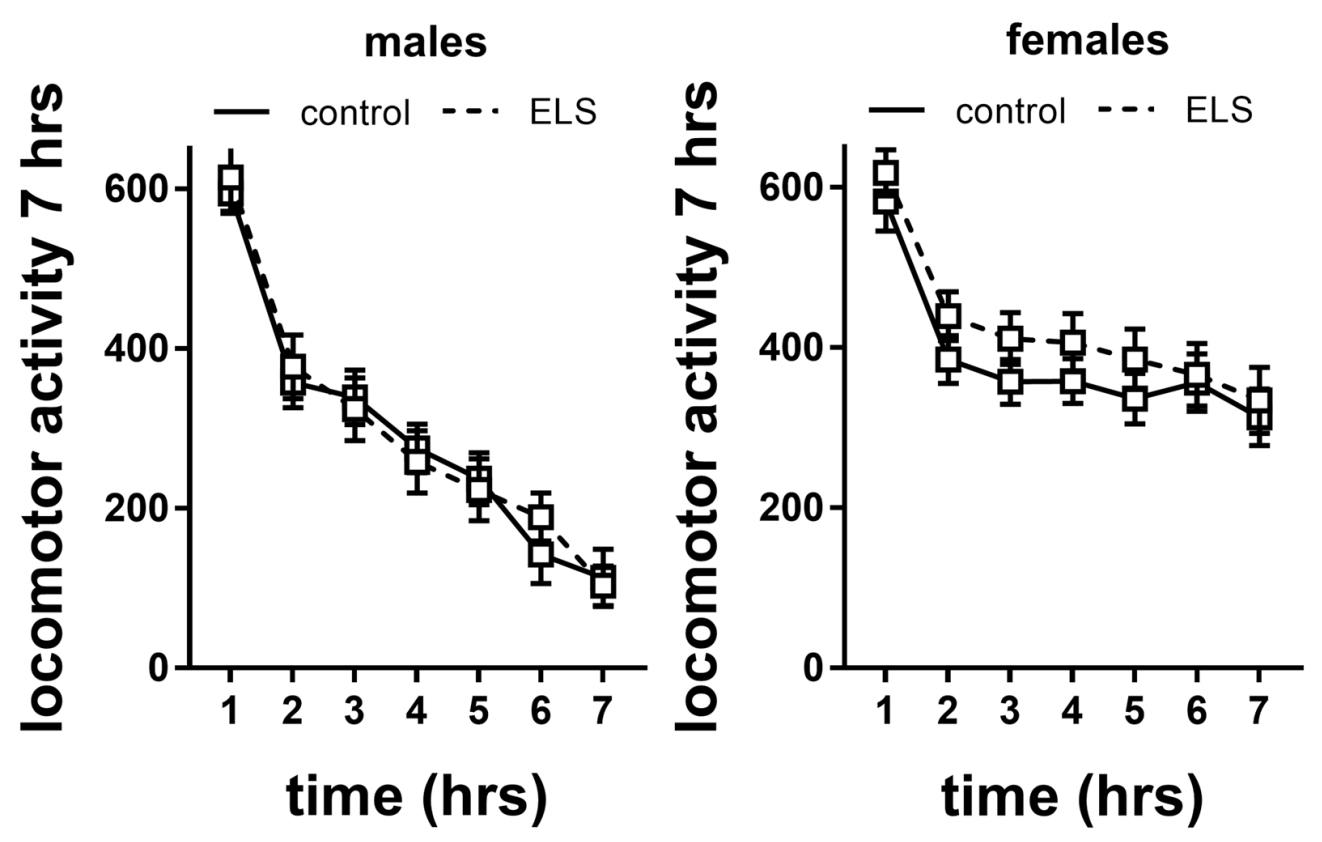

FIGURE 7 | Locomotor activity in males and females exposed to control or ELS condition. Data analyzed with repeated measures ANOVA. $n=28-34$ per group in males; $n=22-26$ per group in females. Locomotor activity = linear combination of standardized distance moved, velocity and time spent moving. Data presented as mean \pm SEM.

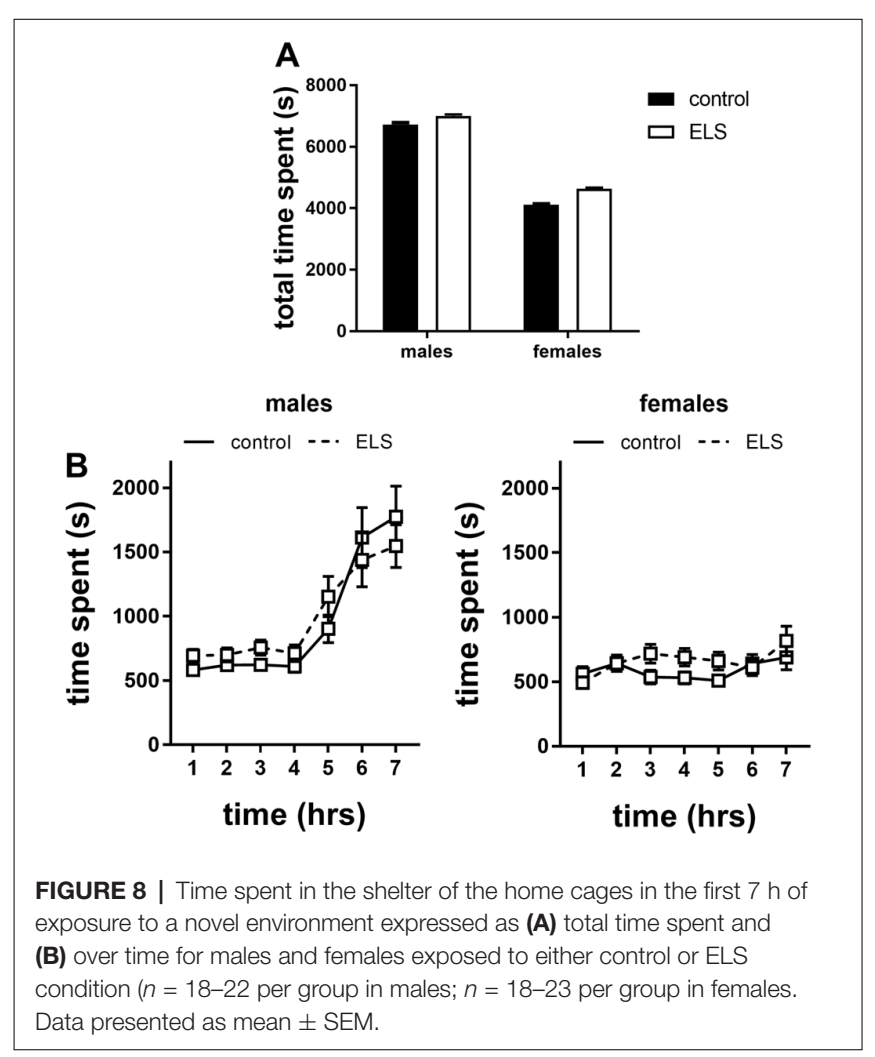

to a novel environment, locomotor activity was increased in both male and female mice, with females adopting a different adaptation strategy than males.

\section{Validity of the Model}

In the current study, the limited nesting and bedding model was used as an environmental challenge to mimic adverse early life conditions in the human situation. This model was originally developed in the Baram lab as a translational tool to investigate the neurobiological underpinnings of early life programming (Brunson, 2005; Rice et al., 2008), in an effort to model the aberrant patterns in maternal behavior often seen in mentally ill or abusive mothers (Walker et al., 2017). Such patterns in maternal-derived signals influence brain circuit maturation important for memory, cognitive and affective functioning thereby promoting resilience or vulnerability to mental illness (Glynn and Baram, 2019).

The limited nesting and bedding model was applied to mice carrying the heterozygous knockout of the MR gene $\mathrm{Nr} 3 \mathrm{C} 2$, to model the vulnerable genetic phenotype of the MR haplotypes that are linked to stress-related psychopathologies (ter Heegde et al., 2015). We confirmed a 50\% reduction in MR expression levels in the hippocampus and tentatively conclude that this animal model is suitable for studying differential expression of MR in the brain with good external validity and generalizability to human findings. It should be noted, however, that the functionality and underlying mechanisms of the MR haplotypes have not yet been extensively investigated (van Leeuwen et al., 2011). We, therefore, cannot exclude the influence of changes additional to the MR expression level (e.g., ligand binding and all functionality involving other proteins) or potential interference of a slight upregulation of GR (Berger et al., 2006). Additionally, although the $\mathrm{Nr} 3 \mathrm{C} 2$ gene encodes both nuclear and membranebound MR, to the best of our knowledge it is not possible 
with the current techniques to verify whether the observed $50 \%$ reduction is proportional in both types. Given the different roles of cytoplasmic and membrane-bound MR (Joëls et al., 2012), this assumption might influence the interpretation of the data. Finally, while Berger et al. (2006) reported that the $\mathrm{MR}_{\text {CamKCre }}$ is reduced at P0 and almost lost at P6, we did not test whether the reduction in MR expression was indeed present at the onset of the ELS paradigm.

\section{HPA Axis Reactivity to Stress}

HPA axis functionality might contribute to variations in disease susceptibility after ELS (Nestler et al., 2002; Heim et al., 2008; de Kloet et al., 2016). The neural circuitry of the HPA axis is highly evolutionary conserved and therefore provides a strong translational measure. Indeed, dysregulation of HPA axis activity is apparent in rodent studies of ELS albeit sometimes with conflicting results (Wang et al., 2012; Molet et al., 2014; McIlwrick et al., 2016; van Bodegom et al., 2017). In our study, indices for HPA axis activity under rest were not affected by ELS, which suggests that ELS-induced changes in the stress system did not impair homeostasis and consequently confound other results. Yet, we cannot exclude changes in HPA axis activity early in life as we did not assess corticosterone levels shortly after the stress paradigm. Evidence from other studies, in fact, point to an early onset of HPA axis dysregulation originating during the stress hyporesponsive period (SHRP; P2-12) with lasting consequences of neuroendocrine programming into adulthood, similar to our study (Sapolsky and Meaney, 1986; McIlwrick et al., 2017).

In line with our hypothesis, we observed striking, opposing sex-dependent ELS differences in the directionality of the transient stress response evoked by a brief period of restraint stress: decreased CORT levels in females and-at trend level-increased levels in males. This is in line with a recent meta-analysis in humans showing sex-differences in HPA axis reactivity related to depression (Zorn et al., 2017).

\section{Role of MR}

We considered the possibility that hippocampal and prefrontal MR (or GR) levels may contribute to the sex-dependent changes in HPA axis reactivity. We report that the limited nesting and bedding model particularly affected MR expression in males. A search of the existing literature resulted in seven articles that investigated ELS-mediated changes of MR expression in the hippocampus, but none for the PFC. They either describe a downregulation (Maccari et al., 1995; Barbazanges et al., 1996), upregulation (Ellenbroek and Cools, 2000; Nasca et al., 2015; Marasco et al., 2016) or no change in MR expression (Wang et al., 2012; van der Doelen et al., 2014). These studies were only conducted in males, investigated mRNAs, differed in the technique used, the exact part of the hippocampus investigated, the ELS model adopted and its timing (pre- or post-natal) which hampers the comparison. Interestingly, among the abovementioned studies, both highly susceptible rats (APOSUS) and mice are characterized by increased MR expression in the hippocampus (Ellenbroek and Cools, 2000; Nasca et al., 2015). Concerning APOSUS rats, it was concluded that the vulnerability was enhanced by maternal behavior since crossfostering ameliorated the phenotype (Ellenbroek and Cools, 2000). We argue that these studies may best resemble the limited nesting model used here as their hallmark is altered quality and not the quantity of maternal behavior (Rice et al., 2008; Glynn and Baram, 2019).

If the upregulation of limbic MR after ELS in males-and no effect in females-would be the main driver of the changes in stress-reactivity, we would expect to see a lower threshold and peak of stress-induced corticosterone levels in ELS males and no change in females; this assumption is based on the inhibitory role of (at least hippocampal) MR on the HPA axis (Joëls and de Kloet, 2017). However, this is not what we observed. One explanation is that the ELS-induced changes in corticosterone response to stress occurs independent of hippocampal MR expression. Rather, the ELS-induced MR increase in males may mitigate the effects of ELS on the corticosterone response, resulting in a relatively modest change in HPA-reactivity. In females there is no such compensatory effect by MR expression, resulting in a stronger phenotype of the stress-induced corticosterone release. However, the overall influence of brain MR on HPA axis reactivity is not only determined by the two areas we presently investigated. For instance, the amygdala exerts a stimulatory role on stressinduced corticosterone release (Ulrich-Lai and Herman, 2009). We cannot exclude that the balance between MR changes in such stimulatory areas outweighs the change in inhibitory regions. This would agree with the observation that reduction of MR expression in (all) CamKII-expressing cells in the forebrain exacerbates the ELS-induced changes in corticosterone release. Finally, the effect of MR is closely linked to GR-dependent processes. Although we did not observe any sex*ELS interaction, the fact that ELS did change GR levels may have consequences for the stress-induced CORT release.

Why male and female mice respond differently to ELS is not explained by our study. The neurobiological mechanisms by which ELS affects stress responsivity are complex. In males, this is most likely due to reduced inhibitory drive to the glutamatergic innervations of the $\mathrm{CRH}$ neurons in the $\mathrm{PVN}$, resulting in elevation of corticosterone levels (Gunn et al., 2013). Yet, the rodent females' literature is limited. Just a few studies addressed this issue experimentally although comparability is hampered due to differences in methodology, with respect to intensity and duration of the stressor, genotype and statistical analysis (Machado et al., 2013; van Bodegom et al., 2017). A possible explanation for the observed ELS-induced hyporeactivity in females comes from rodent experiments on the ultradian rhythm, which suggested that following ELS there is an increase in the frequency of the ultradian pulses, similar to chronic stress (Windle et al., 2008). This results in an increased refractory time in which the animals are in a non-responsive state, giving rise to apparent stress hyporesponsiveness (Windle et al., 2008; Lightman and Conway-Campbell, 2010; Sarabdjitsingh et al., 2010). From a mechanistic perspective, males' and females' differences in MR expression can also be explained by considering influences of progesterone and estrogen on MR expression (Carey et al., 1995; Quinkler et al., 2002; 
Barrett Mueller et al., 2014). Clearly, dedicated neuroendocrine experiments in female rodents are needed to delineate the exact underlying mechanisms investigating the sex-dependency in the observed phenomena.

\section{Behavioral Reactivity to Stress}

Many studies support that exposure to stress during sensitive periods in life can contribute to severe, long-lasting behavioral consequences in affective disorders (Eiland and McEwen, 2012; Pagliaccio et al., 2015; Fonzo et al., 2016). Although little is known how adverse experiences in early life may-interact with the sexually dimorphic programming of the brain, sex differences are apparent (McCauley et al., 1997; Bale and Epperson, 2015).

A vast majority of rodent studies also support that ELS induces changes in behavioral indicators of anxiety later in life (Schmidt et al., 2010; Hartmann et al., 2012; Wang et al., 2012; Cotella et al., 2014; Pan et al., 2014; Sachs et al., 2015; Kanatsou et al., 2016). This is most likely due to ELS-induced accelerated maturation of the fear circuitry, possibly resulting in hyperactivity of the amygdala (Raineki et al., 2012; Bath et al., 2016). In the current study, we tracked behavioral characteristics in a novel environment. We did not find any effect of ELS on anxiety-related behavior although males and females displayed a difference in their adaptation curve. Possibly, (1) females do not adapt to the environment, or (2) females have an enhanced basal activity and minimally respond to a novel environment, therefore reach their baseline sooner. Additional experiments would be required to investigate this.

We selected behavioral reactivity to a novel situation as output parameter, because MR has been in implicated in the adaptation to stress and the appraisal of novel situations in both rodents and humans (Ferguson and Sapolsky, 2007; Schwabe et al., 2013; Arp et al., 2014; Vogel et al., 2016). Specifically, female MR deficient mice seem to be more anxious and lack the behavioral flexibility that is required to rapidly adapt to novel settings and choose appropriate coping strategies in stressful situations (ter Horst et al., 2012, 2013; Joëls and de Kloet, 2017). Conversely, previous studies have argued that overexpression of MR may have anxiolytic effects (Rozeboom et al., 2007; Mitra et al., 2009), albeit not in the context of ELS (Kanatsou et al., 2016, 2017).

\section{CONCLUSION}

Recent human studies reported sex-dependent differences in stress-reactivity, a factor that is known to be sensitive to early life environment and thought to be involved in individuals' susceptibility to depression. This also depends on genetic background e.g., the MR haplotype (Vinkers et al., 2015): In males, the risk to develop depression after childhood maltreatment was dampened if the individuals carried MR

\section{REFERENCES}

Andersen, S. L. (2003). Trajectories of brain development: point of vulnerability or window of opportunity? Neurosci. Biobehav. Rev. 27, 3-18. doi: 10.1016/s01497634(03)00005-8 haplotypes thought to result in low expression. By contrast, these haplotypes resulted in increased vulnerability in females. However, the complex interplay between sex, early life environment and MR background on HPA axis reactivity have not yet been tested in a comprehensive, prospective design. To do so, we reverted to a well-controlled animal study. Our results indeed support that ELS alters HPA axis functioning sex-dependently and that reduction of MR levels exacerbates this pattern in females.

\section{DATA AVAILABILITY}

The raw data supporting the conclusions of this manuscript will be made available by the authors, without undue reservation, to any qualified researcher.

\section{ETHICS STATEMENT}

This study adheres to all above requirements. The current study was approved by the Animal Ethical Committee from Utrecht University, Netherlands. Every effort was taken to minimize animal suffering in accordance with the FELASA guidelines and the Dutch regulation for housing and care of laboratory animals (January 30th 2001/GZB/VVB 2148400).

\section{AUTHOR CONTRIBUTIONS}

$\mathrm{VB}, \mathrm{MA}, \mathrm{RD}$ and RS carried out the experiment. VB, RS and MJ conceived the original idea and wrote the manuscript. VB, MA and RS analyzed the data. LW and OM contributed technically to the experiment. RS supervised the project.

\section{FUNDING}

This work was supported by a Veni grant of Netherlands Organization for Scientific Research (Nederlandse Organisatie voor Wetenschappelijk Onderzoek, NWO grant 863-13-21) to RS. VB, RD and MJ are supported by the Consortium on Individual Development (CID), which is funded through the Gravitation program of the Dutch Ministry of Education, Culture, and Science and Netherlands Organization for Scientific Research (NWO grant 024.001.003).

\section{ACKNOWLEDGMENTS}

We would like to thank Henk Spierenburg and Guus Akkermans for assistance with the genotyping and maintenance of the breeding animals. Marina Wittenberg is kindly acknowledged for her help with the Western Blot analysis.

Arp, J. M., ter Horst, J. P., Kanatsou, S., Fernández, G., Joëls, M., Krugers, H. J., et al. (2014). Mineralocorticoid receptors guide spatial and stimulus-response learning in mice. PLoS One 9:e86236. doi: 10.1371/journal.pone.0086236

Bale, T. L. (2006). Stress sensitivity and the development of affective disorders. Horm. Behav. 50, 529-533. doi: 10.1016/j.yhbeh.2006.06.033 
Bale, T. L., and Epperson, C. N. (2015). Sex differences and stress across the lifespan. Nat. Neurosci. 18, 1413-1420. doi: 10.1038/nn.4112

Barbazanges, A., Piazza, P. V., Le Moal, M., and Maccari, S. (1996). Maternal glucocorticoid secretion mediates long-term effects of prenatal stress. J. Neurosci. 16, 3943-3949. doi: 10.1523/jneurosci.16-12 $-03943.1996$

Barrett Mueller, K., Lu, Q., Mohammad, N. N., Luu, V., McCurley, A., Williams, G. H., et al. (2014). Estrogen receptor inhibits mineralocorticoid receptor transcriptional regulatory function. Endocrinology 155, 4461-4472. doi: 10.1210/en.2014-1270

Bath, K. G., Manzano-Nieves, G., and Goodwill, H. (2016). Early life stress accelerates behavioral and neural maturation of the hippocampus in male mice. Horm. Behav. 82, 64-71. doi: 10.1016/j.yhbeh.2016.04.010

Berger, S., Wolfer, D. P., Selbach, O., Alter, H., Erdmann, G., Reichardt, H. M., et al. (2006). Loss of the limbic mineralocorticoid receptor impairs behavioral plasticity. Proc. Natl. Acad. Sci. U S A 103, 195-200. doi: 10.1073/pnas. 0503878102

Brinks, V., Berger, S., Gass, P., de Kloet, E. R., and Oitzl, M. S. (2009). Mineralocorticoid receptors in control of emotional arousal and fear memory. Horm. Behav. 56, 232-238. doi: 10.1016/j.yhbeh.2009.05.003

Brunson, K. L. (2005). Mechanisms of late-onset cognitive decline after early-life stress. J. Neurosci. 25, 9328-9338. doi: 10.1523/JNEUROSCI.2281-05.2005

Carey, M. P., Deterd, C. H., de Koning, J., Helmerhorst, F., and de Kloet, E. R. (1995). The influence of ovarian steroids on hypothalamic-pituitary-adrenal regulation in the female rat. J. Endocrinol. 144, 311-321. doi: 10.1677/joe.0. 1440311

Carpenter, L. L., Shattuck, T. T., Tyrka, A. R., Geracioti, T. D., and Price, L. H. (2011). Effect of childhood physical abuse on cortisol stress response. Psychopharmacology 214, 367-375. doi: 10.1007/s00213-010-2007-4

Claessens, S. E. F., Daskalakis, N. P., van der Veen, R., Oitzl, M. S., de Kloet, E. R., and Champagne, D. L. (2011). Development of individual differences in stress responsiveness: an overview of factors mediating the outcome of early life experiences. Psychopharmacology 214, 141-154. doi: 10.1007/s00213-0102118-y

Cotella, E. M., Durando, P. E., and Suárez, M. M. (2014). A double-hit model of stress dysregulation in rats: implications for limbic corticosteroid receptors and anxious behavior under amitriptyline treatment. Stress 17, 235-246. doi: 10.3109/10253890.2014.910649

Daskalakis, N. P., Bagot, R. C., Parker, K. J., Vinkers, C. H., and de Kloet, E. R. (2013). The three-hit concept of vulnerability and resilience: toward understanding adaptation to early-life adversity outcome. Psychoneuroendocrinology 38, 1858-1873. doi: 10.1016/j.psyneuen.2013. 06.008

de Kloet, E. R., Joëls, M., and Holsboer, F. (2005). Stress and the brain: from adaptation to disease. Nat. Rev. Neurosci. 6, 463-475. doi: 10.1038/nrn1683

de Kloet, E. R., Otte, C., Kumsta, R., Kok, L., Hillegers, M. H. J., Hasselmann, H., et al. (2016). Stress and depression a crucial role of the mineralocorticoid receptor. J. Neuroendocrinol. 28:12379. doi: 10.1111/jne.12379

de Kloet, E. R., Vreugdenhil, E., Oitzl, M. S., and Joels, M. (1998). Brain corticosteroid receptor balance in health and disease. Endocr. Rev. 19, 269-301. doi: 10.1210/edrv.19.3.0331

DeRijk, R. H., de Kloet, E. R., Zitman, F. G., and van Leeuwen, N. (2011). Mineralocorticoid receptor gene variants as determinants of HPA axis regulation and behavior. Pediatr. Adrenal Dis. 20, 137-148. doi:10.1159/ 000321235

DeSantis, S. M., Baker, N. L., Back, S. E., Spratt, E., Ciolino, J. D., Moran-Santa Maria, M., et al. (2011). Gender differences in the effect of early life trauma on hypothalamic-pituitary-adrenal axis functioning. Depress. Anxiety 28, 383-392. doi: $10.1002 /$ da. 20795

Eiland, L., and McEwen, B. S. (2012). Early life stress followed by subsequent adult chronic stress potentiates anxiety and blunts hippocampal structural remodeling. Hippocampus 22, 82-91. doi: 10.1002/hipo.20862

Ellenbroek, B. A., and Cools, A. R. (2000). The long-term effects of maternal deprivation depend on the genetic background. Neuropsychopharmacology 23, 99-106. doi: 10.1016/S0893-133X(00)00088-9

Ferguson, D., and Sapolsky, R. (2007). Mineralocorticoid receptor overexpression differentially modulates specific phases of spatial and nonspatial memory. J. Neurosci. 27, 8046-8052. doi: 10.1523/JNEUROSCI.1187-07.2007
Fonzo, G. A., Ramsawh, H. J., Flagan, T. M., Simmons, A. N., Sullivan, S. G., Allard, C. B., et al. (2016). Early life stress and the anxious brain: evidence for a neural mechanism linking childhood emotional maltreatment to anxiety in adulthood. Psychol. Med. 46, 1037-1054. doi: 10.1017/s0033291715002603

Fox, J., and Weisberg, S. (2011). An R Companion to Applied Regression. Available online at: http://socserv.socsci.mcmaster.ca/jfox/Books/Companion. Accessed February, 2019.

Gerritsen, L., Milaneschi, Y., Vinkers, C. H., van Hemert, A. M., van Velzen, L., Schmaal, L., et al. (2017). HPA axis genes and their interaction with childhood maltreatment, are related to cortisol levels and stress-related phenotypes. Neuropsychopharmacology 42, 2446-2455. doi: 10.1038/npp.2017.118

Glynn, L. M., and Baram, T. Z. (2019). The influence of unpredictable, fragmented parental signals on the developing brain. Front. Neuroendocrinol. 53:100736. doi: 10.1016/j.yfrne.2019.01.002

Gomez-Sanchez, C. E., De Rodriguez, A. F., Romero, D. G., Estess, J., Warden, M. P., Gomez-Sanchez, M. T., et al. (2006). Development of a panel of monoclonal antibodies against the mineralocorticoid receptor. Endocrinology 147, 1343-1348. doi: 10.1210/en.2005-0860

Gunn, B. G., Cunningham, L., Cooper, M. A., Corteen, N. L., Seifi, M., Swinny, J. D., et al. (2013). Dysfunctional astrocytic and synaptic regulation of hypothalamic glutamatergic transmission in a mouse model of early-life adversity: relevance to neurosteroids and programming of the stress response. J. Neurosci. 33, 19534-19554. doi: 10.1523/JNEUROSCI.1337-13.2013

Hamstra, D. A., de Kloet, E. R., Quataert, I., Jansen, M., and Van der Does, W. (2017). Mineralocorticoid receptor haplotype, estradiol, progesterone and emotional information processing. Psychoneuroendocrinology 76, 162-173. doi: 10.1016/j.psyneuen.2016.11.037

Hartmann, J., Wagner, K. V., Dedic, N., Marinescu, D., Scharf, S. H., Wang, X.D., et al. (2012). Fkbp52 heterozygosity alters behavioral, endocrine and neurogenetic parameters under basal and chronic stress conditions in mice. Psychoneuroendocrinology 37, 2009-2021. doi: 10.1016/j.psyneuen.2012. 04.017

Heim, C., Newport, D. J., Mletzko, T., Miller, A. H., and Nemeroff, C. B. (2008). The link between childhood trauma and depression: insights from HPA axis studies in humans. Psychoneuroendocrinology 33, 693-710. doi: 10.1016/j. psyneuen.2008.03.008

Jankord, R., and Herman, J. P. (2008). Limbic regulation of hypothalamopituitary-adrenocortical function during acute and chronic stress. Ann. N Y Acad. Sci. 1148, 64-73. doi: 10.1196/annals. 1410.012

Joëls, M., and de Kloet, E. R. (2017). 30 years of the mineralocorticoid receptor: the brain mineralocorticoid receptor: a saga in three episodes. J. Endocrinol. 234, T49-T66. doi: 10.1530/JOE-16-0660

Joëls, M., Fernandez, G., Krugers, H., and Karst, H. (2015). Brain mineralocorticoid receptor: the other one. Psychoneuroendocrinology 61:13. doi: 10.1016/j.psyneuen.2015.07.423

Joëls, M., Karst, H., Derijk, R., and Ronald de Kloet, E. (2008). The coming out of the brain mineralocorticoid receptor. Trends Neurosci. 31, 1-7. doi: 10.1016/j. tins.2007.10.005

Joëls, M., Sarabdjitsingh, R. A., and Karst, H. (2012). Unraveling the time domains of corticosteroid hormone influences on brain activity: rapid, slow and chronic modes. Pharmacol. Rev. 64, 901-938. doi: 10.1124/pr.112.005892

Kanatsou, S., Karst, H., Kortesidou, D., van den Akker, R. A., den Blaauwen, J., Harris, A. P., et al. (2017). Overexpression of mineralocorticoid receptors in the mouse forebrain partly alleviates the effects of chronic early life stress on spatial memory, neurogenesis and synaptic function in the dentate gyrus. Front. Cell. Neurosci. 11:132. doi: 10.3389/fncel.2017.00132

Kanatsou, S., Ter Horst, J. P., Harris, A. P., Seckl, J. R., Krugers, H. J., Joëls, M., et al. (2016). Effects of mineralocorticoid receptor overexpression on anxiety and memory after early life stress in female mice. Front. Behav. Neurosci. 9:374. doi: 10.3389/fnbeh.2015.00374

Karst, H., Berger, S., Turiault, M., Tronche, F., Schütz, G., and Joëls, M. (2005). Mineralocorticoid receptors are indispensable for nongenomic modulation of hippocampal glutamate transmission by corticosterone. PNAS 102, 19204-19207. doi: 10.1073/pnas.0507572102

Kas, M. J. H., de Mooij-van Malsen, A. J. G., Olivier, B., Spruijt, B. M., and van Ree, J. M. (2008). Differential genetic regulation of motor activity and anxietyrelated behaviors in mice using an automated home cage task. Behav. Neurosci. 122, 769-776. doi: 10.1037/0735-7044.122.4.769 
Keller, J., Gomez, R., Williams, G., Lembke, A., Lazzeroni, L., Murphy, G. M., et al. (2017). HPA axis in major depression: cortisol, clinical symptomatology and genetic variation predict cognition. Mol. Psychiatry 22, 527-536. doi: 10.1038/mp.2016.120

Klok, M. D., Giltay, E. J., Van der Does, A. J. W., Geleijnse, J. M., Antypa, N., Penninx, B. W. J. H., et al. (2011). A common and functional mineralocorticoid receptor haplotype enhances optimism and protects against depression in females. Transl. Psychiatry 1:e62. doi: 10.1038/tp.2011.59

Knop, J., van IJzendoorn, M. H., Bakermans-Kranenburg, M. J., Joëls, M., and van der Veen, R. (2019). The effects of different rearing conditions on sexual maturation and maternal care in heterozygous mineralocorticoid receptor knockout mice. Horm. Behav. 112, 54-64. doi: 10.1016/j.yhbeh.2019.04.001

Kretz, O., Schmid, W., Berger, S., and Gass, P. (2001). The mineralocorticoid receptor expression in the mouse CNS is conserved during development. Neuroreport 12, 1133-1137. doi: 10.1097/00001756-200105080-00017

Künzel, H. E., Binder, E. B., Nickel, T., Ising, M., Fuchs, B., Majer, M., et al. (2003). Pharmacological and nonpharmacological factors influencing hypothalamicpituitary-adrenocortical axis reactivity in acutely depressed psychiatric inpatients, measured by the Dex-CRH test. Neuropsychopharmacology 28, 2169-2178. doi: 10.1038/sj.npp.1300280

Lightman, S. L., and Conway-Campbell, B. L. (2010). The crucial role of pulsatile activity of the HPA axis for continuous dynamic equilibration. Nat. Rev. Neurosci. 11, 710-718. doi: 10.1038/nrn2914

Loi, M., Mossink, J. C. L., Meerhoff, G. F., Den Blaauwen, J. L., Lucassen, P. J., and Joëls, M. (2015). Effects of early-life stress on cognitive function and hippocampal structure in female rodents. Neuroscience 342, 101-119. doi: 10.1016/j.neuroscience.2015.08.024

Lupien, S. J., McEwen, B. S., Gunnar, M. R., and Heim, C. (2009). Effects of stress throughout the lifespan on the brain, behaviour and cognition. Nat. Rev. Neurosci. 10, 434-445. doi: 10.1038/nrn2639

Maccari, S., Piazza, P. V., Kabbaj, M., Barbazanges, A., Simon, H., and Le Moal, M. (1995). Adoption reverses the long-term impairment in glucocorticoid feedback induced by prenatal stress. J. Neurosci. 15, 110-116. doi: 10.1523/jneurosci.15-01-00110.1995

Machado, T. D., Dalle Molle, R., Laureano, D. P., Portella, A. K., Werlang, I. C. R., da Silva Benetti, C., et al. (2013). Early life stress is associated with anxiety, increased stress responsivity and preference for "comfort foods" in adult female rats. Stress 16, 549-556. doi: 10.3109/10253890.2013.816841

Marasco, V., Herzyk, P., Robinson, J., and Spencer, K. A. (2016). Pre- and post-natal stress programming: developmental exposure to glucocorticoids causes long-term brain-region specific changes to transcriptome in the precocial Japanese quail. J. Neuroendocrinol. 28:12387. doi: 10.1111/jne.12387

McCauley, J., Kern, D. E., Kolodner, K., Dill, L., Schroeder, A. F., DeChant, H. K., et al. (1997). Clinical characteristics of women with a history of childhood abuse: unhealed wounds. JAMA 277, 1362-1368. doi: 10.1001/jama.1997. 03540410040028

McIlwrick, S., Pohl, T., Chen, A., and Touma, C. (2017). Late-onset cognitive impairments after early-life stress are shaped by inherited differences in stress reactivity. Front. Cell. Neurosci. 11:9. doi: 10.3389/fncel.2017.00009

McIlwrick, S., Rechenberg, A., Matthes, M., Burgstaller, J., Schwarzbauer, T., Chen, A., et al. (2016). Genetic predisposition for high stress reactivity amplifies effects of early-life adversity. Psychoneuroendocrinology 70, 85-97. doi: 10.1016/j.psyneuen.2016.04.023

Mitra, R., Ferguson, D., and Sapolsky, R. M. (2009). Mineralocorticoid receptor overexpression in basolateral amygdala reduces corticosterone secretion and anxiety. Biol. Psychiatry 66, 686-690. doi: 10.1016/j.biopsych.2009.04.016

Modell, S., Ising, M., Holsboer, F., and Lauer, C. J. (2005). The munich vulnerability study on affective disorders: premorbid polysomnographic profile of affected high-risk probands. Biol. Psychiatry 58, 694-699. doi: 10.1016/j. biopsych.2005.05.004

Molenhuis, R. T., de Visser, L., Bruining, H., and Kas, M. J. (2014). Enhancing the value of psychiatric mouse models; differential expression of developmental behavioral and cognitive profiles in four inbred strains of mice. Eur. Neuropsychopharmacol. 24, 945-954. doi: 10.1016/j.euroneuro.2014. 01.013

Molet, J., Maras, P. M., Avishai-Eliner, S., and Baram, T. Z. (2014). Naturalistic rodent models of chronic early-life stress. Dev. Psychobiol. 56, 1675-1688. doi: $10.1002 /$ dev. 21230
Moreno-Peral, P., Conejo-Cerón, S., Motrico, E., Rodríguez-Morejón, A., Fernández, A., García-Campayo, J., et al. (2014). Risk factors for the onset of panic and generalised anxiety disorders in the general adult population: a systematic review of cohort studies. J. Affect. Disord. 168, 337-348. doi: 10.1016/j.jad.2014.06.021

Naninck, E. F. G., Hoeijmakers, L., Kakava-Georgiadou, N., Meesters, A., Lazic, S. E., Lucassen, P. J., et al. (2015). Chronic early life stress alters developmental and adult neurogenesis and impairs cognitive function in mice. Hippocampus 25, 309-328. doi: 10.1002/hipo.22374

Nasca, C., Bigio, B., Zelli, D., Nicoletti, F., and Mcewen, B. (2015). Mind the gap: glucocorticoids modulate hippocampal glutamate tone underlying individual differences in stress susceptibility. Mol. Psychiatry 20, 755-763. doi: $10.1038 / \mathrm{mp} .2014 .96$

Nestler, E. J., Barrot, M., DiLeone, R. J., Eisch, A. J., Gold, S. J., and Monteggia, L. M. (2002). Neurobiology of depression. Neuron 34, 13-25. doi: 10.1016/S0896-6273(02)00653-0

Pagliaccio, D., Luby, J. L., Bogdan, R., Agrawal, A., Gaffrey, M. S., Belden, A. C., et al. (2015). Amygdala functional connectivity, HPA axis genetic variation and life stress in children and relations to anxiety and emotion regulation. J. Abnorm. Psychol. 124, 817-833. doi: 10.1037/abn0000094

Pan, P., Fleming, A. S., Lawson, D., Jenkins, J. M., and McGowan, P. O. (2014). Within- and between-litter maternal care alter behavior and gene regulation in female offspring. Behav. Neurosci. 128, 736-748. doi: 10.1037/bne0000014

Pariante, C. M., and Lightman, S. L. (2008). The HPA axis in major depression: classical theories and new developments. Trends Neurosci. 31, 464-468. doi: 10.1016/j.tins.2008.06.006

Quinkler, M., Meyer, B., Bumke-Vogt, C., Grossmann, C., Gruber, U., Oelkers, W., et al. (2002). Agonistic and antagonistic properties of progesterone metabolites at the human mineralocorticoid receptor. Eur. J. Endocrinol. 146, 789-799. doi: 10.1530/eje.0.1460789

Raineki, C., Cortés, M. R., Belnoue, L., and Sullivan, R. M. (2012). Effects of early-life abuse differ across development: infant social behavior deficits are followed by adolescent depressive-like behaviors mediated by the amygdala. J. Neurosci. 32, 7758-7765. doi: 10.1523/JNEUROSCI.5843-11.2012

Reul, J. M., and de Kloet, E. R. (1985). Two receptor systems for corticosterone in rat brain: microdistribution and differential occupation. Endocrinology 117, 2505-2511. doi: 10.1210/endo-117-6-2505

Rice, C. J., Sandman, C. A., Lenjavi, M. R., and Baram, T. Z. (2008). A novel mouse model for acute and long-lasting consequences of early life stress. Endocrinology 149, 4892-4900. doi: 10.1210/en.2008-0633

Rozeboom, A. M., Akil, H., and Seasholtz, A. F. (2007). Mineralocorticoid receptor overexpression in forebrain decreases anxiety-like behavior and alters the stress response in mice. Proc. Natl. Acad. Sci. U S A 104, 4688-4693. doi: 10.1073/pnas.0606067104

Sachs, B. D., Rodriguiz, R. M., Tran, H. L., Iyer, A., Wetsel, W. C., and Caron, M. G. (2015). Serotonin deficiency alters susceptibility to the long-term consequences of adverse early life experience. Psychoneuroendocrinology 53, 69-81. doi: 10.1016/j.psyneuen.2014.12.019

Sapolsky, R. M., and Meaney, M. J. (1986). Maturation of the adrenocortical stress response: neuroendocrine control mechanisms and the stress hyporesponsive period. Brain Res. 396, 64-76. doi: 10.1016/s0006-8993(86)80190-1

Sarabdjitsingh, R. A., Isenia, S., Polman, A., Mijalkovic, J., Lachize, S., Datson, N., et al. (2010). Disrupted corticosterone pulsatile patterns attenuate responsiveness to glucocorticoid signaling in rat brain. Endocrinology 151, 1177-1186. doi: 10.1210/en.2009-1119

Schmidt, M. V., Scharf, S. H., Sterlemann, V., Ganea, K., Liebl, C., Holsboer, F., et al. (2010). High susceptibility to chronic social stress is associated with a depression-like phenotype. Psychoneuroendocrinology 35, 635-643. doi: 10.1016/j.psyneuen.2009.10.002

Schwabe, L., Tegenthoff, M., Höffken, O., and Wolf, O. T. (2013). Mineralocorticoid receptor blockade prevents stress-induced modulation of multiple memory systems in the human brain. Biol. Psychiatry 74, 801-808. doi: 10.1016/j.biopsych.2013.06.001

Strüber, N., Strüber, D., and Roth, G. (2014). Impact of early adversity on glucocorticoid regulation and later mental disorders. Neurosci. Biobehav. Rev. 38, 17-37. doi: 10.1016/j.neubiorev.2013.10.015

Sarubin, N., Hilbert, S., Naumann, F., Zill, P., Wimmer, A. M., Nothdurfter, C., et al. (2017). The sex-dependent role of the glucocorticoid receptor in 
depression: variations in the NR3C1 gene are associated with major depressive disorder in women but not in men. Eur. Arch. Psychiatry Clin. Neurosci. 267, 123-133. doi: 10.1007/s00406-016-0722-5

Team, R. C. (2015). R: a language and environment for statistical computing. $R$ Found. Stat. Comput. Available online at: https://www.r-project.org/. Accessed February, 2019.

ter Heegde, F., De Rijk, R. H., and Vinkers, C. H. (2015). The brain mineralocorticoid receptor and stress resilience. Psychoneuroendocrinology 52, 92-110. doi: 10.1016/j.psyneuen.2014.10.022

ter Horst, J. P., Kentrop, J., Arp, M., Hubens, C. J., de Kloet, E. R., and Oitzl, M. S. (2013). Spatial learning of female mice: a role of the mineralocorticoid receptor during stress and the estrous cycle. Front. Behav. Neurosci. 7:56. doi: 10.3389/fnbeh.2013.00056

ter Horst, J. P., van der Mark, M. H., Arp, M., Berger, S., de Kloet, E. R., and Oitzl, M. S. (2012). Stress or no stress: mineralocorticoid receptors in the forebrain regulate behavioral adaptation. Neurobiol. Learn. Mem. 98, 33-40. doi: 10.1016/j.nlm.2012.04.006

Ulrich-Lai, Y. M., and Herman, J. P. (2009). Neural regulation of endocrine and autonomic stress responses. Nat. Rev. Neurosci. 10, 397-409. doi: $10.1038 / \mathrm{nrn} 2647$

van Bodegom, M., Homberg, J. R., and Henckens, M. J. A. G. (2017). Modulation of the hypothalamic-pituitary-adrenal axis by early life stress exposure. Front. Cell. Neurosci. 11:87. doi: 10.3389/fncel.2017.00087

van Buuren, S., and Groothuis-Oudshoorn, K. (2011). Mice: multivariate imputation by chained equations in R. J. Stat. Softw. 45, 1-67. Available online at: http://www.jstatsoft.org/v45/i03/. Accessed February, 2019.

van der Doelen, R. H. A., Calabrese, F., Guidotti, G., Geenen, B., Riva, M. A., Kozicz, T. T., et al. (2014). Early life stress and serotonin transporter gene variation interact to affect the transcription of the glucocorticoid and mineralocorticoid receptors and the co-chaperone FKBP5, in the adult rat brain. Front. Behav. Neurosci. 8:355. doi: 10.3389/fnbeh.2014. 00355

van Leeuwen, N., Bellingrath, S., de Kloet, E. R., Zitman, F. G., DeRijk, R. H., Kudielka, B. M., et al. (2011). Human mineralocorticoid receptor (MR) gene haplotypes modulate MR expression and transactivation: implication for the stress response. Psychoneuroendocrinology 36, 699-709. doi: 10.1016/j. psyneuen.2010.10.003

van Leeuwen, N., Caprio, M., Blaya, C., Fumeron, F., Sartorato, P., Ronconi, V., et al. (2010). The functional c.-2Gandgt;c variant of the mineralocorticoid receptor modulates blood pressure, renin and aldosterone levels. Hypertension 56, 995-1002. doi: 10.1161/HYPERTENSIONAHA.110. 155630

Varghese, F. P., and Brown, E. S. (2001). The hypothalamic-pituitary-adrenal axis in major depressive disorder: a brief primer for primary care physicians. Prim. Care Companion J. Clin. Psychiatry 3, 151-155. doi: 10.4088/pcc. v03n0401
Vinkers, C. H., Joëls, M., Milaneschi, Y., Gerritsen, L., Kahn, R. S., Penninx, B. W. J. H., et al. (2015). Mineralocorticoid receptor haplotypes sex-dependently moderate depression susceptibility following childhood maltreatment. Psychoneuroendocrinology 54, 90-102. doi: 10.1016/j.psyneuen. 2015.01.018

Vogel, S., Fernández, G., Joëls, M., and Schwabe, L. (2016). Cognitive adaptation under stress: a case for the mineralocorticoid receptor. Trends Cogn. Sci. 20, 192-203. doi: 10.1016/j.tics.2015.12.003

Walker, C.-D., Bath, K. G., Joels, M., Korosi, A., Larauche, M., Lucassen, P. J., et al. (2017). Chronic early life stress induced by limited bedding and nesting (LBN) material in rodents: critical considerations of methodology, outcomes and translational potential. Stress 20, 421-448. doi: 10.1080/10253890.2017. 1343296

Wang, X. D., Labermaier, C., Holsboer, F., Wurst, W., Deussing, J. M., Müller, M. B., et al. (2012). Early-life stress-induced anxiety-related behavior in adult mice partially requires forebrain corticotropin-releasing hormone receptor 1. Eur. J. Neurosci. 36, 2360-2367. doi: 10.1111/j.1460-9568.2012. 08148.x

Windle, R. J., Wood, S. A., Kershaw, Y. M., Lightman, S. L., Ingram, C. D., and Harbuz, M. S. (2008). Increased corticosterone pulse frequency during adjuvant-induced arthritis and its relationship to alterations in stress responsiveness. J. Neuroendocrinol. 13, 905-911. doi: 10.1046/j.1365-2826. 2001.00715.x

Wingenfeld, K., and Otte, C. (2019). Mineralocorticoid receptor function and cognition in health and disease. Psychoneuroendocrinology 105, 25-35. doi: 10.1016/j.psyneuen.2018.09.010

Young, E. A., Abelson, J. L., and Cameron, O. G. (2004). Effect of comorbid anxiety disorders on the hypothalamic-pituitary-adrenal axis response to a social stressor in major depression. Biol. Psychiatry 56, 113-120. doi: 10.1016/j. biopsych.2004.03.017

Zorn, J. V., Schür, R. R., Boks, M. P., Kahn, R. S., Joëls, M., and Vinkers, C. H. (2017). Cortisol stress reactivity across psychiatric disorders: a systematic review and meta-analysis. Psychoneuroendocrinology 77, 25-36. doi: 10.1016/j. psyneuen.2016.11.036

Conflict of Interest Statement: The authors declare that the research was conducted in the absence of any commercial or financial relationships that could be construed as a potential conflict of interest.

Copyright (C) 2019 Bonapersona, Damsteegt, Adams, van Weert, Meijer, Joëls and Sarabdjitsingh. This is an open-access article distributed under the terms of the Creative Commons Attribution License (CC BY). The use, distribution or reproduction in other forums is permitted, provided the original author(s) and the copyright owner(s) are credited and that the original publication in this journal is cited, in accordance with accepted academic practice. No use, distribution or reproduction is permitted which does not comply with these terms. 